\title{
The Quest for Citations: Drivers of Article Impact
}

\author{
Stefan Stremersch, Isabel Verniers and Peter C. Verhoef
}

\begin{tabular}{|l|l|}
\hline \multicolumn{2}{|l|}{ ERIM REPORT SERIES RESEARCH IN MANAGEMENT } \\
\hline ERIM Report Series reference number & ERS-2006-061-MKT \\
\hline Publication & September 2006 \\
\hline Number of pages & 51 \\
\hline Persistent paper URL & \\
\hline Email address corresponding author & stremersch@few.eur.nl \\
\hline Address & Erasmus Research Institute of Management (ERIM) \\
& RSM Erasmus University / Erasmus School of Economics \\
& Erasmus Universiteit Rotterdam \\
& P.O.Box 1738 \\
& 3000 DR Rotterdam, The Netherlands \\
& Phone: + 31104081182 \\
& Fax: $\quad+31104089640$ \\
& Email: info@erim.eur.nl \\
& Internet: www.erim.eur.nl \\
\hline
\end{tabular}

Bibliographic data and classifications of all the ERIM reports are also available on the ERIM website: www.erim.eur.nl 


\section{ERASMUS RESEARCH INSTITUTE OF MANAGEMENT}

\section{REPORT SERIES}

\section{RESEARCH IN MANAGEMENT}

\begin{tabular}{|c|c|}
\hline \multicolumn{2}{|c|}{ ABSTRACT AND KEYWORDS } \\
\hline Abstract & $\begin{array}{l}\text { Why do some articles become building blocks for future scholars, while many others remain } \\
\text { unnoticed? We aim to answer this question by contrasting, synthesizing and simultaneously } \\
\text { testing three scientometric perspectives - universalism, social constructivism and presentation - } \\
\text { on the influence of article and author characteristics on article citations. To do so, we study all } \\
\text { articles published in a sample of five major journals in marketing from } 1990 \text { to } 2002 \text { that are } \\
\text { central to the discipline. We count the number of citations each of these articles has received } \\
\text { and regress this count on an extensive set of characteristics of the article (i.e. article quality, } \\
\text { article domain, title length, the use of attention grabbers and expositional clarity), and the author } \\
\text { (i.e. author visibility and author personal promotion). We find that the number of citations an } \\
\text { article in the marketing discipline receives, depends upon "what one says" (quality and domain), } \\
\text { on "who says it" (author visibility and personal promotion) and not so much on "how one says it" } \\
\text { (title length, the use of attention grabbers, and expositional clarity). Our insights contribute to the } \\
\text { marketing literature and are relevant to scientific stakeholders, such as the management of } \\
\text { scientific journals and individual academic scholars, as they strive to maximize citations. They } \\
\text { are also relevant to marketing practitioners. They inform practitioners on characteristics of the } \\
\text { academic journals in marketing and their relevance to decisions they face. On the other hand, } \\
\text { they also raise challenges towards making our journals accessible and relevant to marketing } \\
\text { practitioners: (1) authors visible to academics are not necessarily visible to practitioners; (2) the } \\
\text { readability of an article may hurt academic credibility and impact, while it may be instrumental in } \\
\text { influencing practitioners; (3) it remains questionable whether articles that academics assess to } \\
\text { be of high quality are also managerially relevant. }\end{array}$ \\
\hline Free Keywords & Scientometrics, Citation Analysis, Cite, Referencing, Impact \\
\hline Availability & $\begin{array}{l}\text { The ERIM Report Series is distributed through the following platforms: } \\
\text { Academic Repository at Erasmus University (DEAR), DEAR ERIM Series Portal } \\
\text { Social Science Research Network (SSRN), SSRN ERIM Series Webpage } \\
\text { Research Papers in Economics (REPEC), } \underline{\text { REPEC ERIM Series Webpage }}\end{array}$ \\
\hline Classifications & $\begin{array}{l}\text { The electronic versions of the papers in the ERIM report Series contain bibliographic metadata } \\
\text { by the following classification systems: } \\
\text { Library of Congress Classification, (LCC) LCC Webpage } \\
\text { Journal of Economic Literature, (JEL), JEL Webpage } \\
\text { ACM Computing Classification System CCS Webpage } \\
\text { Inspec Classification scheme (ICS), ICS Webpage }\end{array}$ \\
\hline
\end{tabular}




\title{
The Quest for Citations:
}

\section{Drivers of Article Impact}

\author{
Stefan Stremersch, Isabel Verniers and Peter C. Verhoef
}

WORKING PAPER

September 2006

Stefan Stremersch is Professor of Marketing, School of Economics, Erasmus University of Rotterdam, the Netherlands and Visiting Associate Professor of Marketing, Goizueta Business School, Emory University, Atlanta, Georgia, U.S. Isabel Verniers is a PhD Candidate in Marketing at the Faculty of Economics and Business Administration, Ghent University, Belgium. Peter C. Verhoef is Professor of Marketing, University of Groningen, the Netherlands. This paper was written when the second author was a visiting scholar at Erasmus University Rotterdam, the Netherlands. We acknowledge financial support of the Erasmus Institute for Research in Management (ERIM) and SOM and the data support of Ton Van Raan, Thed Van Leeuwen, Peter Negenborn and Clara Calero of CWTS, Leiden University, the Netherlands. We thank Lutgart Verraes, Jan Van Waes and Stijn Van Waes for their research assistance. This paper has benefited from the comments of Marnik Dekimpe, Bas Donkers, Bruce Hardie, Jan-Benedict Steenkamp, Christophe Van den Bulte, Stijn Van Osselaer and Sriram Venkataraman, in earlier stages of development.

\section{Correspondence Address}

Stefan Stremersch, Department of Marketing (H15-01), School of Economics, Erasmus University Rotterdam, Burg. Oudlaan 50, PO Box 1738, 3000 DR Rotterdam. Phone: +31.10.408.12.89. Fax: +31.10.408.91.69. E-mail: stremersch@few.eur.nl. 


\title{
The Quest for Citations: Drivers of Article Impact
}

\begin{abstract}
Why do some articles become building blocks for future scholars, while many others remain unnoticed? We aim to answer this question by contrasting, synthesizing and simultaneously testing three scientometric perspectives - universalism, social constructivism and presentation - on the influence of article and author characteristics on article citations. To do so, we study all articles published in a sample of five major journals in marketing from 1990 to 2002 that are central to the discipline. We count the number of citations each of these articles has received and regress this count on an extensive set of characteristics of the article (i.e. article quality, article domain, title length, the use of attention grabbers and expositional clarity), and the author (i.e. author visibility and author personal promotion). We find that the number of citations an article in the marketing discipline receives, depends upon “what one says” (quality and domain), on “who says it” (author visibility and personal promotion) and not so much on "how one says it" (title length, the use of attention grabbers, and expositional clarity). Our insights contribute to the marketing literature and are relevant to scientific stakeholders, such as the management of scientific journals and individual academic scholars, as they strive to maximize citations. They are also relevant to marketing practitioners. They inform practitioners on characteristics of the academic journals in marketing and their relevance to decisions they face. On the other hand, they also raise challenges towards making our journals accessible and relevant to marketing practitioners: (1) authors visible to academics are not necessarily visible to practitioners; (2) the readability of an article may hurt academic credibility and impact, while it may be instrumental in influencing practitioners; (3) it remains questionable whether articles that academics assess to be of high quality are also managerially relevant.
\end{abstract}

Keywords: scientometrics, citation analysis, cite, referencing, impact. 


\section{Introduction}

"What makes an article influential? Why do some articles have enormous impact on the field, and others practically none? As both students and professionals, all of us read articles that stay with us for the rest of our lives, other articles are forgotten...” (Sternberg and Gordeeva 1996, p. 69)

The saying “publish or perish” rules a great part of assistant professors’ professional lives in the race for tenure. However, to what extent the field pays attention to what an academic publishes, determines the rest of his/her academic career. It is common to look at the citations published work has received for evaluating promotions to full and chaired professor, to evaluate the collective impact of a department or school and to evaluate the standing of our journals. "Yet, despite the widely acknowledged importance of citations, many scholars have noted that we know little about the factors that influence whether a given paper, and therefore a given scholar, is cited.” (Baldi 1998, p. 829) The science of measuring and analyzing science to address such issues is called scientometrics.

Prior studies in marketing have studied diverse scientometric issues. Bettencourt and Houston (2001a) identify which method types and which subject areas receive more attention. Hoffman and Holbrook (1993) introduce a two-stage procedure to investigate the underlying structure of author cocitations. Leong (1989) examines the reference source nature for articles published in Journal of Consumer Research. Cote, Leong and Cote (1991) study the influence of Journal of Consumer Research on other disciplines, while Baumgartner and Pieters do the same for International Journal of Research in Marketing (Pieters et al. 1999), marketing journals in general (Baumgartner and Pieters 2003) and economic journals in general (Pieters and Baumgartner 2002). Zinkhan, Roth and Saxton (1992) document the mutual exchange (both referencing to and from) between Journal of Consumer Research and other disciplines. Tellis, Chandy and Ackerman (1999) studied four major journals (Journal of Consumer Research, Journal of Marketing, Journal of Marketing Research, Marketing Science) and examined to what extent they are diverse in their references. This topic was later revisited for Journal of Consumer Research, Journal of Marketing and Journal of Marketing Research by 
Bettencourt and Houston (2001b). Stremersch and Verhoef (2005) studied globalization of authorship in the marketing discipline and found it increased diversity in the field, but hurt the impact of several major journals. Goldenberg, Libai and Muller (2005) characterized co-author networks in marketing along several focal network measures. Recently, Bauerly, Johnson, and Singh (2005) have pointed to the importance of readability of a marketing article for creating impact. Also, (prior) editors of major marketing journals have stressed the importance of presentation and readability (e.g. Mick 2005; Staelin 2002).

The focal question of the present paper is: How do scientometric characteristics of article and author(s) affect the citations an article receives in the marketing discipline? This question - to the best of our knowledge - has remained unstudied so far. To answer this question, we will contrast and synthesize three theoretical perspectives on the drivers of citations and test them simultaneously on a sample of five major marketing journals over a 13 year time span. Doing so allows us to explain why some articles in marketing have been heavily cited, while many others remained unnoticed.

We will embed the theory we develop in prior, though fragmented, scientometric work in other disciplines. Bayer (1982) examined drivers of citations in the marriage and family literature and found that the literature a paper connects to and the authors' eminence affect article impact. Van Dalen and Henkens (2001) show that characteristics of the authors, visibility, content and journals significantly affect the impact of articles in demography. Peters and Van Raan (1994) find in chemical engineering that mainly author reputation and number of references affect article impact. Baldi (1998) examines which characteristics of two papers in astrophysics influence the probability that a citation exists from the citing to the cited paper. In line with the earlier findings of Stewart (1983), in geology, he found that articles mostly have influence for what they say, not for who the authors are.

Gaining an understanding on the effects of scientometric characteristics of an article and its author(s) on the number of times an article is cited is very relevant to the discipline. Individual 
researchers and journals alike try to maximize the number of times they are cited. For individual researchers, the number of citations is a dominant criterion for promotion, salary increases and funding. It also will determine to what extent the individual researcher is seen as a thought leader in a certain field of inquiry. For journals, the number of citations determines to a large extent their prestige. Journal prestige, in turn, will translate into subscriptions - the likelihood of libraries and individual scholars to subscribe increases with prestige - and an ability to attract high-quality and novel manuscripts - researchers’ preference to submit their best work to a journal increases with journal prestige. For practitioners, a clear understanding of the different characteristics underlying scholarly work in marketing is relevant as it informs them on its relevance to decision areas they face and the extent to which academic journals in marketing may provide good sources for new marketing knowledge in the future.

The next section develops the scientometric theory we developed in the present study and presents our research hypotheses. The third section discusses our data. The fourth section explains our analysis methodology and presents the results. The fifth section discusses our findings, develops implications for different scientific stakeholders, considers the limitations and presents avenues for future research.

\section{Theory}

We discern three perspectives on the influence of scientometric characteristics of article and author(s) on the citations an article receives (for our conceptual framework, see Figure 1). The first is the universalist perspective. The universalist view on science states that the reward structure of science is openness and based on a cognitive procedure (Baldi 1998). Therefore, article characteristics such as its cognitive content determine article citations (Van Dalen and Henkens 2001). The second is the social constructivist perspective. Social constructivists claim that extra-scientific and functionally 
irrelevant author characteristics, such as author eminence (Baldi 1998), play a significant role in the allocation of citations. The third is the presentation perspective. While fragmented, the claim that underlies the presentation perspective is that articles have impact for how they present theory, study and findings. We develop specific predictions for each perspective.

\section{The universalist perspective}

The universalist perspective is that articles are cited for "what” the authors say. We distinguish two different dimensions within this perspective. A first dimension is the quality of the article. A second dimension is the domain of the article.

The quality of an article may affect the extent to which it is cited. High quality articles may represent bigger breakthroughs and therefore be path-breaking. Therefore, they may provide more inspiration to future research. High quality articles may also present findings of higher reliability, as compared to low quality articles and therefore be more able to convincingly persuade (Gilbert 1977). Thus, high quality articles may be cited more than low quality articles.

The domain of the article may affect citations as well. Domains may differ in orientation (behavioral, quantitative and managerial), method type - the method the article uses (conceptual, empirical, methodological and mathematical) - and subject area - the subject on which the article focuses (e.g. advertising, new products, relationship marketing) - and thereby may contain articles that are more or less cited for several reasons. First, domains may differ in size. Prior research has shown that smaller domains attract fewer citations than larger domains (King 1987). Second, domains may differ in the extent to which they are relevant to one another. One domain may have relevance to more other domains than another domain, by which it may attract more citations (Stewart 1983). Third, domains may differ in the extent to which they have reached maturity. Domains that are new may represent bigger breakthroughs, as compared to domains that are mature. Therefore the articles in new 
domains may be cited more than articles in mature domains (Sternberg and Gordeeva 1996). Fourth, there may be divergence in citation practices across domains, e.g. the citation practice in one domain may be to frequently cite other articles in the same domain, while the citation practice in another domain may be to cite articles from other disciplines (Van Dalen and Henkens 2004).

We may derive the following hypothesis:

H1: Universal characteristics of an article affect the times the article is cited, in that (a) quality positively affects the number of cites; and (b) domain affects the number of cites.

\section{The social constructivist perspective}

The social constructivist perspective is that articles have impact for "who" the authors of an article are. We discern two different dimensions within this perspective. A first dimension is visibility. A second dimension is personal promotion.

Merton (1968) introduced the Matthew effect in science. It is named after the Gospel According to Matthew (ch. 25, vs. 29), "for unto everyone that hath shall be given and he shall have abundance: but from him that hath not shall be taken away even that which he hath" and "consists in the accruing of greater increments of recognition for particular scientific contributions to scientists of considerable repute and the withholding of such recognition from scientists who have not yet made their mark” (Merton 1968, p. 58). His arguments are that “a scientific contribution will have greater visibility when it is introduced by a scientist of high rank, rather than when it is introduced by one who has not yet made his mark” (Merton 1968, p. 59). As such, we may expect that the work of academics with longer publication records, with positions on the editorial boards of prestigious journals, or holding an appointment at highly ranked business schools (Bergh, Perry and Hanke 2006) will receive more attention, for the same contribution, as compared to academics of lower standing. Visibility of authors may also affect article citations in other ways. Stremersch and Verhoef (2005) have shown - in 
the marketing discipline - that articles authored by international scholars are cited less than articles by U.S.-based scholars. The theoretical reasoning they develop is that international authors may be disadvantaged in visibility when the majority of the domain is U.S.-based. Goldenberg, Libai and Muller (2005) have illustrated co-author networks in marketing and argued that more connected scholars are more important in a scientific network. Therefore, work of more connected scholars can transfer more easily to the scientific network and receive more citations. Finally, the number of authors may also increase visibility. As scholars have different opportunities to present their work, at conferences, research camps, doctoral programs, and the like, the number of opportunities at which the work can be presented is bound to go up with the number of authors.

Personal promotion of academic scholars is often a cause for shame rather than pride. While personal promotion may be an important driver of impact, some have raised concerns that it is driven by vanity (Bayer 1982). Self-referencing is one form of personal promotion (Van Dalen and Klamer 2005). First, it shows that the authors have confidence in the findings and it may underscore the importance of the work. If you do not cite your own work, why should others cite it? Compare this with finance, if you are not willing to invest in your own company, why should anyone else? Second, while one paper may not have been noticed by peers, a follow-up paper may be and therefore generate renewed interest in the original article. In that sense, good personal promotion also relates to the programmatic development of one’s research (Bayer 1982). Another characteristic of a good salesman is the use of the norm of reciprocity (Cialdini 1988; Jacobs, et al. 2001). Reciprocity is "a social interaction where movement of one party evokes a compensating movement in some other party” (Houston and Gassenheimer 1987, p. 11). Scholars may feel indebted to scholars who cite their work and therefore may also be more inclined to return the cite, or "you cite me, I'll cite you" reciprocity. Thus, the extent to which scholars cite other people's work (which we term reference intensity), may also make their own work more cited. 
H2: Social constructivist characteristics of an article affect the times the article is cited, in that (a) visibility positively affects the number of cites; and (b) personal promotion positively affects the number of cites.

\section{The presentation perspective}

The presentation perspective is that articles are cited for "how" the authors say what they say. We discern three different dimensions within this perspective. A first dimension is title length. A second dimension is the use of attention grabbers. A third is expositional clarity.

The title of an article is a very important element of any scientific or scholarly article, as it draws a reader's attention and is used in electronic databases to store, search and retrieve articles (Yitzhaki 2002). However, we know little about its effect on article citations. Longer article titles are more informative and thus may perform their functions more effectively, but they may also hint at article complexity (Yitzhaki 2002). Therefore, the direction of the effect of title length on article citations is difficult to posit ex ante.

A second dimension of presentation is the extent to which attention grabbers are included. Attention grabbers are words that have a special appeal because they raise attention. For instance, the word "new" in the title may hint to novelty of the article and therefore positively influence the number of times an article is cited (Van Dalen and Klamer 2005). While unstudied so far, one may also expect that the usage of the name of the discipline itself in the title may have special appeal to and thus grab attention of a large cross-section of scholars in that discipline. Finally, also keywords may grab attention. Keywords are important as it is by keywords that search engines search databases. Especially in today's school environments, electronic searches are becoming more important in the search and retrieval of scientific articles. While keywords obviously overlap strongly with method types and subject areas, and thus are capturing universalist characteristics, the number of keywords 
may increase the likelihood of citation, as it increases the chance that the article appears in bibliographic searches.

Expositional clarity is the clarity with which an article explains what it says. This can be done by giving a graphic illustration of the conceptual model, adding tables that explain estimation issues or

robustness checks, and referring complex issues to appendices to improve the flow of a paper. Also the use of equations or footnotes can affect clarity, although this effect may be context dependent. For instance, while the usage of many equations may be found more clarifying by mathematicians or statisticians, it can be obfuscating in other sciences, such as the social sciences. Expositional clarity can also be operationalized by formal indices of readability in linguistics (Flesch 1948). One such example is the Flesch formula: 206.835 - (.846* [number of syllables per 100 words] $)-(1.015 *$ [average number of words per sentence]). Overall, with increasing clarity an article may be better able to promote its content and be more accessible for a wider audience.

H3: Presentation characteristics of an article affect the times the article is cited, in that (a) title length affects the number of cites; (b) the usage of attention grabbers positively affects the number of cites; and (c) expositional clarity positively affects the number of cites.

\section{Data}

In this section, we detail our data. First, we describe our sample. Second, we detail our measures. Third, we describe our sample along the identified measures.

\section{Sample}

As representative of the marketing discipline, we sampled five major journals, IJRM (International Journal of Research in Marketing), JCR (Journal of Consumer Research), JM (Journal of Marketing), JMR (Journal of Marketing Research) and MKS (Marketing Science). These journals correspond with the journals used by Stremersch and Verhoef (2005). Tellis, Chandy and Ackerman 
(1999) argue that JCR, JM, JMR and MKS may be a good representation of the field. However, all of these journals are U.S.-based journals, for which reason we also include an international journal, of which IJRM is probably the best representative.

We inventoried all articles published in JCR, JM, JMR and MKS (1990-2002), and IJRM (1997-2002). IJRM enters the ISI SSCI only in 1997. We excluded any papers with 3 pages or less (as these would be editorials, software and book reviews, and the like). Our final sample consisted of 1,825 articles, 508 that appeared in JCR, 351 that appeared in JM, 504 that appeared in JMR, 328 that appeared in MKS and 134 that appeared in IJRM.

\section{Measures}

We next detail our measures, first the dependent variable and then all independent variables (for an overview see Appendix A).

\section{Dependent variable}

An article is "cited", when it is mentioned in the reference list of another article. We operationalize the number of citations as the number of citations in academic journals, net of selfcitations, a paper has received until December 31, 2004, from journals in the ISI-SSCI. Thus, the number of citations is the total number of occasions on which an article appeared in the reference list of articles in journals, that are included in the ISI-SSCI, which contains a wide set of scientific journals. This data set was generated in August 2005 by an automatic algorithm, run by a specialized institute in scientometric research (Center for Science and Technology Studies, at Leiden University, the Netherlands), with a subscription to ISI's databases.

The usage of citations, net of self-citations, is fairly common in the - admittedly sparse scientometric literature on the drivers of article influence (e.g. articles reviewed in the introduction). Citations are an objective measure of influence, impact or attention (Pieters and Baumgartner 2002). 


\section{Independent variables}

We next detail our independent variables, organized along the lines of the framework from which they are derived, be it a universal, social constructivist or presentation framework, providing their symbols we will use later on in-between brackets.

\section{Universalist perspective}

We discerned two dimensions within the universalist perspective, article quality and domain of the article. Rather than assess article quality ourselves, which would be inherently flawed, we relied on the quality assessment of editors and the editorial board. As one may consider article order (u1) as the editor's assessment of the strength of the contribution of a paper, article order may be a first indicator of article quality (Smart and Waldfogel 1996; Van Dalen and Henkens 2001). This also seems true in marketing (at least we could rule out one alternative ordering - alphabetically on the name of the first author - which the marketing journals we study do not consistently use). Article order is a reverse-coded measure, going from 1 (lead article) to $n$ (last article in issue). ${ }^{1}$

As one may consider journal awards (u2) chosen by the entire editorial board (typically in marketing between 50-100 leading scholars) as the choice of the highest quality article by leading scholars, awards may be a second indicator. We include a dummy for winning one of the following best paper awards, Best Article Award (IJRM), Best Article Award (JCR), Harold D. Maynard Award (JM), MSI/H. Paul Root Award (JM), Paul Green Award (JMR), William F. O’Dell Award (JMR), and John D.C. Little Award (MKS). ${ }^{2}$

A third indicator of quality may be article length (u3), as editors often provide very specific guidance to authors on the length they will allow for the manuscript, in function of its contribution (i.e.

\footnotetext{
${ }^{1}$ As some editors may only chose the lead article based on quality, rather than the complete order of articles, this may be an alternative indicator of quality. We will test it as such in the empirical section.

${ }^{2}$ Note that selection of articles for awards is not based on number of citations, as they are chosen at the end of the publication year and thus citations did not have time to materialize yet. One exception in this respect is the O’Dell Award, which is only chosen five years after publication, but our results are robust to the exclusion of the O’Dell award.
} 
contribution to length ratio). We operationalize article length as the number of pages of the article. As the number of pages may be actively managed by the editor in function of the magnitude of the contribution (Peters and Van Raan 1994), it may be highly collinear with article order. However, in our sample of marketing journals, this appears not to be the case. The correlation between article length and article order is -.40. The reason for this relatively low correlation may be that while article order is the editor's prerogative, article length may also be influenced by the reviewers' assessment of the contribution of the article.

Prior research has discerned two categories of article domain, namely method type and subject area (Tellis, Chandy and Ackerman 1999). We add a third, namely orientation. Orientation refers to whether the article has a behavioral (u4), quantitative (u5) or managerial orientation. We dropped the managerial orientation variable from our empirical tests, as it showed a very high correlation with behavioral orientation (-0.81). We code u4 as 1 when the article has a behavioral orientation ( 0 otherwise) and u5 as 1 when the article has a quantitative orientation (0 otherwise). When the article covered more than one orientation, all the respective orientations were assigned the value 1 . The content coding towards these orientations was done by the second author. The coding is based on Kerin’s (1996) description of marketing as a behavioral science, quantitative science and managerial activity. As this author had doubts about the assessment on 37 articles, the first author independently assessed these articles. Then the first and second author compared their assessment on these 37 articles, and found that only 2 differed, which were then assigned after discussion. Thus, the reliability of the procedure is high.

Method type (u6-u9) is the method the article uses. The second author examined all abstracts of the 1,825 articles and classified them based on the presence of keywords for: (1) conceptual (conceptual, theoretical, concept, theory); (2) empirical (empirical or the type of study, such as secondary data, interview, field study, etc.); (3) methodological (new methodology, new method, 
methodological); and (4) analytical (mathematical, analytical, mathematical equation). This procedure is similar to Tellis, Chandy and Ackerman (1999). If the abstract did not identify any significant keyword hinting at the method type, the introduction of the paper was examined $(<20 \%)$, and in rare cases $(<1 \%)$, the entire article was studied. The first and second author discussed all cases in which there could be doubt on the method type, seeking input from experts in the respective fields if necessary. Articles can use multiple method types.

Subject area (u10-u28) is the subject on which the article focuses. We used a similar - to the identification of method type - procedure to identify subject area, although rather than directly classifying papers into categories, articles were described by a set of keywords that actually appeared in the abstract. In total, we used approximately 1,150 keywords. These keywords were then re-grouped first in 41 subgroups and then in 19 subject areas that we defined after frequent deliberation among coauthors. The reliability of this classification was assessed by the following procedure. JM and JMR each periodically publish the classification in subject areas for all articles they publish, using their own subject areas. We assessed the overlap in the subject area classification by both journals with our classification of all articles in these two journals. In $84.2 \%$ of all cases, there was a perfect overlap between our classification and the classification by JM and JMR. In 8\% of all cases, JM and JMR also identified other subject areas in addition to the ones we identified. When this was the case, we reexamined the article and in $21 \%$ of such cases, we also included that additional subject area. In $7.8 \%$ of all cases, JM and JMR did not identify the subject area we identified. In such cases, we again reexamined the article, and we reverted to the journal's assessment in $15 \%$ of such cases, but kept our own article classification in all other cases. Overall, these results show high reliability of our 
categorization if one compares them to inter-rater reliabilities that are deemed to be acceptable (85\%) (Kassarjian 1977; Tellis, Chandy and Ackerman 1999). ${ }^{3}$ Articles can belong to multiple subject areas.

\section{Social constructivist perspective}

We discern two different dimensions within the social constructivist perspective, visibility and personal promotion. We operationalize visibility through the use of multiple measures. To reflect Merton's Matthew effect, we use: (1) publication record (c1) of the authors, by summing all authors' prior publications in IJRM, JCR, JM, JMR, and MKS, since the journals' inception, (2) editorial board membership (c2), by including a dummy variable, indicating whether at least one of the authors has been a member of at least one of the editorial boards of the journals we study between the year of publication of the article and two years after publication date ( 1 if this is the case, 0 if this is not the case); and (3) the ranking of the business school (c3) at which the authors hold a position, by taking the average business school ranking in 2004 (provided by the Financial Times) across all authors. Business school ranking is a reverse-scored variable. Articles of which the authors are affiliated to a business school with a high ranking, have a low value while articles of which the authors are affiliated to a business school with a low ranking, have a high value.

To reflect the other mechanisms described in the theory section, we also include, centrality (c4), U.S. affiliation (c5) and number of authors (c6). Centrality is the minimum across the authors on the paper of their individual centrality in the discipline. In order to find one researcher's centrality, one has to find the shortest route of this author to all other researchers (based on co-author relationships) and then compute the average across all of these paths (for more information, see Goldenberg, Libai and Muller 2005). We inventoried this measure for each author in our database from the website www.mconnectivity.com; out of 1,688 authors, 82 authors yielded missing values and 46 authors did

\footnotetext{
${ }^{3}$ We do not have such data on the other journals, IJRM, JCR and MKS, and therefore we cannot conduct a similar analysis. While our analysis shows that our classification is reliable for JM and JMR and we see no reason to expect any different for the other journals, the reliability for these other journals may be higher or lower.
} 
not yield a value as they were too separated to calculate centrality. ${ }^{4}$ We used the April 2005 update of the website to inventory this measure. Information requested from www.mconnectivity.com, revealed that the delay in the update is minimum 2 months and maximum 5 months. Thus, April 2005 is the best update to use given that our dependent variable was based on all citations until December 31, 2004. Note that centrality is a reverse-scored variable. Articles of which at least one of the authors is very central to the discipline - i.e. co-authored with many different researchers that in turn co-authored with many different researchers - have a low value, while articles of which all the authors are not central to the discipline - i.e. have co-authored with relatively few different researchers that in turn coauthored with few different researchers - have a high value. U.S. affiliation is the share of all authors that have a U.S. affiliation, as stated on the paper and inventoried by using procedures similar to Stremersch and Verhoef (2005). Number of authors is the number of authors stated on the paper.

We also operationalize personal promotion through the use of multiple measures to reflect our theoretical arguments above. Reference intensity (c7) is the number of references cited by the article. Self-citation intensity (c8) is the number of times the authors have self-cited the paper in future work until December 31, 2004.

\section{Presentation perspective}

We discerned three dimensions in the presentation perspective, title length, the use of attention grabbers, and expositional clarity. Title length (p1) is the number of significant words in the title, following procedures used earlier by Yitzhaki (2002). Attention grabbers (p2-p5) are dummy variables for words in the title ( 1 when the word is included in the title, 0 when this is not the case) that have a special appeal because they raise attention, such as “marketing” (p2), “market” (p3), “new” (p4), and

\footnotetext{
${ }^{4}$ Also the two other variables of the marketing connectivity project by Goldenberg, Libai and Muller (2005) were inventoried and included in the models presented below. However, the Lehmann number showed high collinearity with the average centrality, while the number of co-authors showed high collinearity with author publication record. Therefore, both were dropped from the analyses and we only include the centrality measure.
} 
the number of keywords that are supplied by ISI (p5). The word “new” may hint at novelty (Van Dalen and Klamer 2005). The words "marketing” and "market” may be related to the core of the discipline. The number of keywords may affect the likelihood with which the paper is retrieved in electronic database searches.

Expositional clarity is measured by number of equations (p6), number of figures (p7), number of tables (p8), number of footnotes (p9) and number of appendices (p10), inspired by Ayres and Vars (2000), and reading ease (p11), inspired by the linguistics literature (Flesch 1948).

\section{Sample description}

This section describes our sample, first our dependent variable, and then our independent variables.

\section{Dependent variable}

A first way to characterize article citations in our sample is to examine how many cites the median article in marketing obtains. Figure 2 displays the number of citations, excluding self-citations, the median article in each of the years in our sample has obtained to date. We present these numbers for the median article across journals and also per journal (as per December 31, 2004). Overall, articles in the Journal of Marketing are cited more often than articles in any other major marketing journal. On the other hand, International Journal of Research in Marketing is less cited than any other major marketing journal.

A second way is to examine, which are the most influential articles in the marketing discipline. Evidently, a simple look at the raw number of cites a paper received by December 31, 2004, may provide only limited insights. The number of cites an article receives is by definition driven by the age of the article, which is commonly modeled using a quadratic time trend (also see, Ayres and Vars 2000; Landes and Posner 1996). Therefore we specify the following equation: 


$$
\operatorname{CITE}_{k}=\alpha+\gamma * Q_{k}+\lambda * Q_{k}^{2}+\varepsilon_{k}
$$

$C I T E_{k}$ is the number of citations received by an article $k$ (excluding self-citations). The multiplicative terms capture the time dependence in citations, in which $Q_{k}$ represents the number of quarters that the article $k$ has been out. As the procedure developed by Cameron and Trivedi (1990) shows that there is substantial overdispersion ( $p<0.01)$, we estimate the model specified in (1) as a negative binomial model, and estimate it using quasi maximum likelihood procedures and the quadratic hill climbing optimization algorithm that does not suffer from this problem. We can subsequently rank all articles on the residual $\varepsilon_{k}$ of equation (1). From this ranking, one may distill Table 1, which provides an overview of the 20 most cited papers.

\section{Independent variables}

Table 2 describes our sample of articles along the drivers of citations. We offer a historical perspective in blocs of 2 years (except for the first year, 1990) in Appendix B, as that may also show how the discipline has evolved over time, but do not discuss it at length, for reasons of brevity. The first column in Table 2 contains the driver. Column 3 contains a single number (that is a count) when it concerns the number of papers in an orientation (u4-u5), method type (u6-u9) and subject area (u10$\mathrm{u} 28$ ), and the number of papers with attention grabbing words in the title (p2-p4). Column 3 contains the average and the range in square brackets, for all other variables. In Appendix B, columns 3-9 contain the average (u1-u3, c1-c8, p1, p5-p11) or the count (u4-u28, p2-p4) of all these variables for the sub-periods.

At the level of the entire sample, for the variables in the universalist perspective, we conclude that $4 \%$ of all papers win a best paper award and average article length is 14.4 pages. Most papers have a behavioral orientation. Most papers in the marketing discipline also are empirical and develop a conceptual theory. As can be seen in Appendix B, this is a constant through the period 1990-2002. 
Brand and product management, methodology, strategy, consumer knowledge and advertising are the biggest subject areas. In a historical perspective, the subject areas that have undergone a rise in interest are brand and product management (in the last two years), retailing (at the end of the 90s) and Ecommerce (especially at the turn of the century).

We next discuss the social constructivist variables. The sum of prior articles by authors (publication record), being 10.8 over the entire sample, consistently increased, with rising maturity of the marketing discipline. While 10.8 may be surprisingly high, note that this is the sum of prior articles by all authors on the paper. Given that the average number of authors is 2.2 , the average number of prior articles per author for the journals in our database is 4.9 . On average, $63 \%$ of all articles published in 1990-2002 in these five journals involve an editorial board member of any of these five journals. This has changed little over time. The average business school ranking for the authors of an article is 59.1, while the average centrality is 6.0. As the Appendix B shows, the average share of U.S. authors declined from 0.9 to 0.7, an evolution also illustrated by Stremersch and Verhoef (2005), while its overall sample mean is 0.8 . The average number of references increased quite steeply from around 40 in beginning of the 90 s to around 50 in most recent years, while the overall sample mean is 46 . The average number of self-citations is 2.1 .

The last bloc contains the presentation variables. Articles have titles with an average count of 7 significant words and include 6 keywords on the average. The average article has 4 equations, 2 figures, 3 tables, and 6 footnotes. One in every two articles have an appendix and the Flesch reading ease is 23 on the average, which is considered very difficult (Bauerly, Johnson and Singh 2005).

\section{Analysis}

This section first discusses the model we estimate to explain citations, after which we turn to fit and robustness of the model. Third, we present the estimates and hypothesis tests. 


\section{Model}

To assess the influence of article and author characteristics on citations, we specify the following model:

$$
C I T E_{k j}=\alpha+\sum_{i=1}^{4}\left(\beta_{i} * D_{i}\right)+\gamma_{j} Q_{k j}+\lambda_{j} Q_{k j}^{2}+\sum_{r=1}^{R} \mu_{r} * u_{r k j}+\sum_{s=1}^{S} \delta_{s} * c_{s k j}+\sum_{t=1}^{T} \theta_{t} * p_{t k j}+\varepsilon_{k j}
$$

with $D_{i}=1$, when $i=j$, 0 otherwise.

$C I T E_{k j}$ represents the number of cites an article $k$ in journal $j$ gathers. $D_{i}$ represent the journal dummies (with MKS being the base alternative of which the main effect is captured in the intercept). The multiplicative terms capture the time dependence in citations, in which $Q_{k j}$ represents the number of quarters that the article has been out. Thus, we allow the time dependence to vary across journals. The meaning of the other variables is as follows: $\mu_{r}$ are parameters capturing the effects of universalist drivers of citations $u_{1}$ to $u_{R},(R=28), \delta_{s}$ are parameters capturing social constructivist drivers of citations $c_{1}$ to $c_{S}(S=8)$, and $\theta_{t}$ are parameters capturing the effects of presentation drivers of citations $p_{1}$ to $p_{T}(T=11)$. We again estimate this equation using a negative binomial specification, estimated with a quasi maximum likelihood procedure and the quadratic hill climbing optimization algorithm. We present our estimates and fit statistics in Table 3. In addition to the model in equation (2) (model 4), we estimate three models, (1) a universalism model (nested model 1), (2) a social constructivism model (nested model 2), and (3) a presentation model (nested model 3). The number of observations is 1,757, but drops to 1,531 when the number of keywords (p5) is included, as it suffers from missing values.

\section{Fit and robustness}

The Likelihood Ratio Index (LRI; also called McFadden’s R-squared) of our full model (as in equation 2) is 0.241 . This is satisfactory given the complex phenomenon we aim to explain and the property of the LRI to be substantially lower than a regular R-squared measure. We also report the 
Akaike Information Criterion (AIC) and the Schwarz criterion (SIC). The fit statistics for nested models 1-3 show that model 1 (universalist perspective) has the highest fit $(\mathrm{LR}$-index $=0.128)$, model 2 (social constructivist perspective) has the second highest fit (LR-index $=0.096)$ and model 3, the lowest fit $($ LR-index $=0.080)$. We found that all models $(1-4)$ provided a better fit to the data than a restricted model that only contained the other variables for which we controlled (journal dummies, including their interactions with time and time-squared).

We conducted several robustness checks. First, the models 1-4 in Table 3 show that the estimates are relatively similar across model specifications. Except for number of appendices, none of the variables changes sign. Significance levels are affected to some extent for several reasons, including the increasing number of parameters that are estimated (although there were no signs of harmful collinearity) and the drop in the number of observations when presentation is added (due to missing values on the number of keywords).

Second, as some journals, on the average, have more articles per issue or more pages per article, one may also standardize such variables. We ran all our analyses with standardized variables and standardization does not affect any of our findings.

Third, one may argue that IJRM is a journal of a different nature than the other four: (1) it has a very different and more diverse geographic background; and (2) we have data on far fewer articles in IJRM than any of the other five journals in our sample. Therefore, we ran all our analyses without including any IJRM articles. The results we found are very similar.

Fourth, we also explored non-linear effects of, for instance, article length, productivity, centrality, title length and the expositional variables by incorporating quadratic effects of these variables. However, the inclusion of none of these quadratic effects improves the model fit. We also explored interaction effects. Included interaction effects did not improve model fit and were unstable. 
Fifth, we tested different methods of controlling for the age of an article in several ways. A first method was to include $q+\ln q$ as a time trend, rather than $q+q^{2}$. The model results were exactly the same. A second method was to fix the duration we allow for a paper to obtain citations. We fixed this duration to 4 years. Our findings were again the same, except for one estimate (capturing the influence of the subject area "other") that turned less significant and one estimate that turned more significant (capturing the influence of the subject area "retailing"). Two more estimates turned more significant (for tables and appendices), but their sign was counter to theoretical expectations (= negative).

Sixth, one may wonder whether the effect of article order is continuous as is modeled now or whether it is reflective of a "lead article" phenomenon. To test this, we also estimated a model in which the variable article order was replaced with a lead article variable, taking the value of 1 when the article was the lead article in an issue, taking the value of 0 when the article was not the lead article in an issue. We found similar results. For the awards variable, one may argue that as the O'Dell award considers a long time period (5 years), the award committee may include the number of cites of a paper as an implicit criterion leading to endogeneity. We therefore, also estimated a model in which the O'Dell award is not taken into account. We found very similar results.

Seventh, business school rankings are always debated no matter the source. We also operationalized this variable using Business Week’s rankings and have tried different types of operationalizations (dummies when the school was included in the ranking or not, average rank across authors, minimum rank across authors). The results remain highly similar. The reason for reporting the measure based on the Financial Times, rather than the measure based on Business Week, is that Business Week is more U.S.-based, while Financial Times is perceived to be more global. We next detail our estimates and hypothesis testing. 


\section{Hypothesis Testing}

Table 4 provides an overview of our hypotheses, the underlying theoretical arguments and the results of our testing. The latter are based on the findings for the individual effects in Table 3, which we next discuss. Confirming $\mathrm{H}_{1 \mathrm{a}}$, we find that article quality - as reflected by article order $\left(\mu_{1}=-0.02\right.$; $\mathrm{p}<0.05$; reverse-scaled), awards $\left(\mu_{2}=0.34, \mathrm{p}<0.01\right)$ and article length $\left(\mu_{3}=0.04, \mathrm{p}<0.01\right)-$ has a significant positive effect on article citations.

We also find that domain affects article citations. This mostly seems to apply to the subject area and less to the orientation or the method type (papers with methodological $\left(\mu_{8}=-0.24 ; \mathrm{p}<0.01\right)$ and analytical theory $\left(\mu_{9}=-0.41 ; \mathrm{p}<0.01\right)$ method types are cited less, as compared to conceptual theory and empirical papers, in nested model 1, but not in the full model). Articles on relationship marketing $\left(\mu_{12}=0.55 ; \mathrm{p}<0.01\right)$, services marketing $\left(\mu_{21}=0.53, \mathrm{p}<0.01\right)$ and E-commerce $\left(\mu_{28}=\right.$ $0.77, \mathrm{p}<0.01)$ tend to be cited more than other articles, while articles on advertising $\left(\mu_{14}=-0.28, \mathrm{p}<\right.$ $0.01)$, sales $\left(\mu_{19}=-0.32, \mathrm{p}<0.01\right)$, consumer knowledge $\left(\mu_{22}=-0.14 ; \mathrm{p}<0.05\right)$ and other topics $\left(\mu_{27}=\right.$ $-0.23, \mathrm{p}<0.05$ ) tend to be cited less than other articles. Given full confirmation of $\mathrm{H}_{1 \mathrm{a}}$ and partial confirmation of $\mathrm{H}_{1 \mathrm{~b}}$, we find support for the universalist perspective on article citations.

Providing partial confirmation for the positive effect of visibility on article citations $\left(\mathrm{H}_{2 \mathrm{a}}\right)$, we find that publication record $\left(\delta_{1}=0.00, \mathrm{p}<0.10\right)$, editorial board membership $\left(\delta_{2}=0.14, \mathrm{p}<0.01\right)$, business school ranking ( $\delta_{3}=-0.00, \mathrm{p}<0.01$; reverse-scaled) positively affect the number of cites an article receives, but the effects we find for centrality $\left(\delta_{4}=0.10, \mathrm{p}<0.05\right.$; reverse-scaled $)$ and number of authors $\left(\delta_{6}=-0.06, \mathrm{p}<0.05\right)$ run counter to our expectations. One reason why the articles of central authors may receive fewer citations than the articles written by authors that are less central to the discipline may be that - in addition to visibility - they differ in content. The contributions of central authors may be more incremental, while impactful breakthroughs may especially develop at the boundaries of the discipline. One reason why papers with more authors may be less influential than 
papers with fewer authors is that authors may be less committed to promote the paper when there are many authors, because of lack of intellectual ownership. Thus, visibility of an article may actually decrease with increasing number of authors. Finally, we find that the effect of U.S. affiliation turns insignificant in the full model (as compared to nested model 2). This contrasts with earlier research by Stremersch and Verhoef (2005) and may have two predominant reasons. First, U.S. author affiliation may co-vary with other author and article characteristics, already covered by the other variables we include in the full model. Second, the significant drop in number of observations (in the full model, as compared to nested model 2) increases the threshold for significance.

Providing partial confirmation for $\mathrm{H}_{2 b}$, we find that personal promotion - as operationalizated by self-citation intensity $\left(\delta_{8}=0.08, \mathrm{p}<0.01\right)$ - positively affects the number of citations an article receives, while it does not do so, when operationalized as reference intensity $\left(\delta_{7}=0.00, \mathrm{p}>0.10\right)$.

Overall, we find support for the social constructivist perspective on the number of citations an article receives.

In contrast, we find very fragile evidence for the presentation perspective, as postulated in hypotheses $\mathrm{H}_{3 a}, \mathrm{H}_{3 b}$, and $\mathrm{H}_{3 c}$. We find that title length does not affect the number of citations. Thus, we do not find any confirmation for $\mathrm{H}_{3 \mathrm{a}}$.

Attention grabbers in marketing do not seem as effective as we postulated. The effects are inconsistent across models, and overall very weak. The only effect that is significant, although it is only marginally significant is the use of the word "market" $\left(\theta_{3}=0.14, \mathrm{p}<0.10\right)$. However, closer inspection showed that this is entirely due to the term market orientation, which became a very impactful concept in marketing (See Table 1). We conclude that we do not find any confirmation for $\mathrm{H}_{3 \mathrm{~b}}$.

Also the results for expositional clarity are mixed, at best. We find that there is a negative effect of the number of equations $\left(\theta_{6}=-0.01, \mathrm{p}<0.05\right)$ and a positive effect of the number of 
appendices $\left(\theta_{10}=0.00, \mathrm{p}<0.01\right)$ on citations. Contrary to our expectations, we find that reading ease negatively affects citations $\left(\theta_{11}=-0.02, \mathrm{p}<0.01\right)$. The reason may be that expositional clarity, in general, and readability specifically, may not always be considered positive by peers. Metoyer-Duran (1993) finds higher readability scores among rejected than among accepted papers and Armstrong (1980) finds that peers rate less readable papers of higher quality, even when the content is exactly the same. Overall, we conclude that the evidence for $\mathrm{H}_{3 \mathrm{c}}$ is mixed, at best.

\section{Discussion}

\section{Conclusion}

In this paper, we contrasted, synthesized and simultaneously tested three theoretical perspectives on the influence of article and author(s) characteristics on the number of citations an article receives. We found full or partial confirmation for the universalist and social constructivist view on science, while we found virtually no confirmation for the presentation view on science. Our findings contribute to the marketing and scientometrics literatures. Towards marketing, this study is, as far as we know, the first study to examine drivers of article citations in a comprehensive and structured manner. Given the recent surge in attention for scientometric issues in the marketing discipline, this paper is likely to stimulate intense debate - both positive and negative. However, this debate among marketing scholars is highly needed, not only for the marketing discipline’s sake... If marketing scholars do not debate drivers of citations (which is essentially a "marketing of science" problem), who else should, can, or will?

Towards scientometrics, this study adds to the few scientometric studies that aim to explain article citations. It is the first to rigorously develop and simultaneously test the above three perspectives and come to a clear synthesis. It also adds new variables to prior operationalizations of these three perspectives, such as awards (in the universalistic perspective), editorial board 
membership, business school ranking, centrality, and self-citation intensity (in the social constructivist perspective), title length and attention grabbers that refer to the domain (in the presentation perspective).

\section{Implications for scientific stakeholders}

Our research has several implications for scientific stakeholders. We discern two main scientific stakeholders, namely the management of scientific journals (editor, editorial board, sponsoring associations and publisher) and the academic scholar.

\section{The management of journals}

Managers of scientific journals strive to maximize the impact of their journal and thus the articles it publishes. The present paper shows that not only quality - which in its widest meaning is the dominant "acceptance" criterion used by journals - should be a concern of editors. Several other considerations should come into play.

First, editors should be aware of the influence particular domains may have. We identified subject areas in which articles typically receive more cites than average. We found that articles in the E-commerce domain wielded the greatest influence and have been truly path-breaking as they mark the start of an entire new line of research. The relative higher impact for articles on services and relationships reflects the increasing importance of these two domains in marketing in recent years (Vargo and Lush 2004). Following this development, editors have called for more research in this area (e.g. Bolton 2003). When one does decide for other reasons, to nurture domains of which papers have less influence than average, managers of journals may seek alternative means of promoting this work (e.g. adding a special conference, commentaries, etc.).

A second consideration is article length, for which we found it positively affects citations. As article length is important, there is a clear argument for journals to "invest" in more journal space, 
even if the number of submissions and acceptances remains constant. This fits the recent conceptual argument on journal space by McAlister in the Journal of Marketing (McAlister 2005).

Third, as highly productive scholars generally have more influence, a fair question is whether editors should strive to stimulate submissions from such authors. This could be done by actively soliciting or inviting manuscripts from these authors and visiting departments with many productive scholars upon appointment as editor in order to have a sufficient number of publications from these scholars. While the first has been implemented by Journal of Marketing Research (e.g. under the term of the late Dick Wittink), the second advice is followed by almost all editors that took tenure at a major marketing journal the last five years. However, one may also criticize such an approach. While it may increase the journal's impact, it may also enhance the Matthew effect in science, which may conflict with the "true" (universalist) motivation of scientists.

Fourth, our findings also suggest challenges for editors towards making their journal more relevant to practitioners. First, the Matthew effect cited above is contained within marketing academia. Practitioners may have their own pecking order. Thus, strengthening the Matthew effect may be detrimental to practical relevance. Second, it is conceivable that more readable papers may have a bigger impact on practice. At the same time, however, we find it may hurt citations, by negatively affecting an article's credibility. Thus, editors must engage in a balancing act between the academic audience and their (potential) practitioner audience.

Fifth, our finding that personal promotion - as operationalized by self-citation intensity affects article citations also has implications for journals. Reviewers as well as editors should probably be lenient on self-citations and not necessarily see them as vanity of the researcher, but rather as a sign of programmatic development and good personal promotion. 


\section{The academic scholar}

As our research shows that high quality research is cited more than low quality research, the prime stimulus of academics to produce new knowledge with high rigor remains. However, our study does have some clear implications for the individual academic scholar that may not be straightforward or at least not always on academics’ minds.

First, career orientation towards specific subject areas is an important consideration. While of course, such decisions are driven by interest and expertise, an academic scholar that seeks strong influence in the discipline, may also account for other aspects, such as the influence prior work in these areas has typically wielded. Obviously, subject areas’ popularity itself evolves over time, and thus the results in Table 3 can not guide towards the future, but are only a reflection of the past.

Second, as publication record affects citations through visibility, it may be worthwhile to cooperate with highly experienced co-authors, when one does not have much of a record one self.

Third, in the review process, some editors may push authors towards reducing paper length. In our personal experience, and from talking to colleagues, authors seem to comply quite easily with these guidelines. However, our results encourage authors to "fight back" on this and, rather than immediately conceding to editors, devote more effort to convincing editors that the paper size is appropriate, through emphasizing the contribution they make to the literature. That is, if the disagreement on paper size stems from a lack of information on the editor's part, rather than an overly positive assessment of the author towards his/her own work.

\section{Implications for practitioners}

The present paper also has several implications for practitioners. First, Table 2 and Appendix B inventory the marketing discipline along many different characteristics and the evolution therein over the period 1990-2002. This is informative to practitioners, as it shows, for instance, to what extent the discipline or journals can reflect on decision areas they face. 
Second, Table 1 contains the 20 papers that have - corrected for time - made the biggest impact on the advancement of scientific knowledge in the marketing discipline. An academically interested marketer may consider reading these top 20 articles to develop an understanding of important paradigms in marketing.

Third, our results at least hint that articles that aim to have a high impact in marketing science may be quite different from articles that aim to have a high impact on marketing practice. For instance, social constructivist characteristics of authors that positively influence academic citations (such as editorial board membership and self-citation behavior) may be quite different from social constructivist characteristics of authors that positively influence impact in practice. The latter include very likely membership of business communities, rather than editorial board membership, and referencing in business press and newspapers, rather than self-citations in academic journals. The fact that the academic community may have a different pecking order (e.g. the Matthew effect) than practitioners, is problematic, given that the elements that determine the academic pecking order may be very idiosyncratic to marketing academia and may not be relevant to practitioners.

Fourth, our results on presentation hint that scientific impact does not have much to gain from expositional clarity. If researchers act to maximize citations (which seems to be the current driving force at many top-notch business schools), this finding does not hold great promise for the future readability of our journals for practitioners. While journals and scholars alike should act to build stronger bridges with practice, the question remains whether our top-notch journals will provide good (and readable!) sources to practitioners for new marketing knowledge in the future, a concern also expressed by Bauerly, Johnson and Singh (2005).

Fifth, it is encouraging that we find that article quality is the most important driver of citations. However, whether there is a relationship between what academics judge to be a high quality article and what practitioners deem relevant, is something that needs further investigation. 


\section{Research limitations}

First, while we discern different method types of articles, we did not distinguish different empirical methodologies, within the empirical method type. Future research that investigates differentiation between methodologies would be most helpful, but it should go a step further than merely differentiating between lab experiments and field data, as was done in prior studies (e.g. Bettencourt and Houston 2001a; Tellis, Chandy and Ackerman 1999). A related limitation that also applies to the subject area variables is the inherent flaws in categorization. While we see no way in which categorization could be improved upon and our method seems to compare favorably to other categorizations in accuracy, it is a matter of concern and should lead to caution in the interpretation of our findings.

Second, we focused on the number of cites an article generates, net of self-cites. This is consistent with prior scientometric studies on influence or attention. However, focusing on citations also has shortcomings (Baumgartner and Pieters 2003). For example, article citations may not always reflect transfer of knowledge or intellectual indebtedness, but may for instance also be irrelevant or be driven by strategic considerations, e.g. citing a possible reviewer (Baumgartner and Pieters 2003). Therefore, future research that examines other measures of influence may be very fruitful. We can think of: (1) the amount of press attention (e.g. citations in Wall Street Journal, Economist, or Business Week) a scientific article obtains, (2) the amount of educational attention (e.g. inclusion in textbooks, marketing classics volumes, or B-school class readings) it gets, and (3) the amount of “web” attention (e.g. downloads) it gets.

Third, some of our measures for our independent variables are limited. We measure article quality by article order, awards and article length, but these measures may also be related to visibility. Visibility is a different causal mechanism than quality and based on our measures we may not be able to clearly separate out both mechanisms. While future studies that develop better quality indicators 
may evidently be valuable, it is unclear what indicators those would be. One alternative one may consider is a judgment by experts.

Finally, this paper opens up new issues that are not necessarily shortcomings of the present study. First, we still understand little about citation patterns at the individual article level. E.g. why does paper A cite paper B? Research that builds upon prior insights and method by Baldi (1998) promises to be quite fruitful. Such research would also have high relevance towards marketing, given that it can be tied to prior work on the influence of marketing in other domains (e.g. the work of Baumgartner and Pieters) and co-author networks (Goldenberg, Libai and Muller 2005). It can also be tied to our finding regarding editorial board membership. We found editorial board members to be more cited than scholars that are not a member of an editorial board. Considerable gamesmanship in citing editorial board members may underlie this finding. One course one can take to investigate this issue is to examine whether joining the board of a journal causes a regime break in the number of citations for articles in that same journal that were (co-)authored by that new board member. The difficulty of such research endeavor is in determining the appropriate time lag to consider as the effect takes place upon submission, not upon publication, of an article.

Second, how do disciplines compare to each other in the factors that drive article citations? For instance, how does the marketing discipline compare to other business disciplines, or some of its source disciplines, such as economics, sociology and psychology? Also how do the social sciences compare to the natural sciences? These are all valid questions worthy of empirical investigation.

Third, we focus almost exclusively on the impact of articles on further scientific development, through citations. However, a vast area remains unexplored, namely what is the influence of our scientific articles on marketing practice? Empirical investigation of this question is of very high importance to our field. 
In sum, this paper contributes to early scientometric insights on the influence of article and author characteristics on article citations, but leaves many related issues open for further investigation. However, as the quest for citations is one of the prime extrinsic motivations to scientists, it deserves more of our attention. 


\section{Table 1:}

\section{Most Cited Papers Between 1990-2002 (Controlling for Time)}

\begin{tabular}{clcc}
\hline Rank & Top 20 Most Cited (corrected for time) & $\begin{array}{c}\text { Journal } \\
\text { (Publication Year) }\end{array}$ & $\begin{array}{c}\text { Nr of Citations } \\
\text { (absolute number, Dec 2004) }\end{array}$ \\
\hline 1 & Hoffman and Novak & JM (1996) & 227 \\
2 & Jaworski and Kohli & JM (1993) & 347 \\
3 & Anderson and Narus & JM (1990) & 384 \\
4 & Fournier & JCR (1998) & 124 \\
5 & Kohli and Jaworski & JM (1990) & 373 \\
6 & Narver and Slater & JM (1990) & 358 \\
7 & Doney and Cannon & JM (1997) & 170 \\
8 & Cronin and Taylor & JM (1992) & 337 \\
9 & Day & JM (1994) & 263 \\
10 & Alba, Lynch, Weitz, Janiszewski, Lutz, Sawyer and Wood & JM (1997) & 153 \\
11 & Ganesan & JM (1994) & 254 \\
12 & Zeithaml, Berry and Parasuraman & JM (1996) & 178 \\
13 & Muniz and O’Guinn & JCR (2001) & 34 \\
14 & Novak, Hoffman and Yung & MKS (2000) & 63 \\
15 & Bettman, Luce and Payne & JCR (1998) & 95 \\
16 & Lynch and Ariely & MKS (2000) & 60 \\
17 & Garbarino and Johnson & JM (1999) & 76 \\
18 & Slater and Narver & JM (1995) & 185 \\
19 & Bitner & JM (1990) & 260 \\
20 & Webster & JM (1992) & 236 \\
\hline
\end{tabular}




\section{Table 2:}

\section{Sample Characteristics for Independent Variables}

\begin{tabular}{|c|c|c|}
\hline & Value & Entire sample \\
\hline \multicolumn{3}{|l|}{ Universalist Perspective } \\
\hline Quality - Article order (R) & average [range] & $4.5[1 ; 27]$ \\
\hline Quality - Awards & average [range] & $0.04[0 ; 1]$ \\
\hline Quality - Article length & average [range] & $14.4[4 ; 35]$ \\
\hline \multicolumn{3}{|l|}{ Domain } \\
\hline Orientation - Behavioral & count & 1190 \\
\hline Orientation - Quantitative & count & 483 \\
\hline Method Type - Conceptual & count & 754 \\
\hline Method Type - Empirical & count & 1412 \\
\hline Method Type - Methodological & count & 342 \\
\hline Method Type - Analytical & count & 297 \\
\hline Subject Area - New Products & count & 132 \\
\hline Subject Area - B2B & count & 186 \\
\hline Subject Area - Relationship & count & 91 \\
\hline Subject Area - Brand and Product & count & 303 \\
\hline Subject Area - Advertising & count & 218 \\
\hline Subject Area - Pricing & count & 132 \\
\hline Subject Area - Promotions & count & 75 \\
\hline Subject Area - Retailing & count & 72 \\
\hline Subject Area - Strategy & count & 228 \\
\hline Subject Area - Sales & count & 78 \\
\hline Subject Area - Methodology & count & 255 \\
\hline Subject Area - Services & count & 61 \\
\hline Subject Area - Consumer Knowledge & count & 225 \\
\hline Subject Area - Consumer Emotions & count & 143 \\
\hline Subject Area - Other Consumer Behavior & count & 92 \\
\hline Subject Area - Consumption Behavior & count & 145 \\
\hline Subject Area - International Marketing & count & 54 \\
\hline Subject Area - Other & count & 87 \\
\hline Subject Area - E-commerce & count & 28 \\
\hline \multicolumn{3}{|l|}{ Social Constructivist Perspective } \\
\hline Visibility - Publication record & average [range] & $10.8[0 ; 83]$ \\
\hline Visibility - Editorial board membership & average [range] & $0.6[0 ; 1]$ \\
\hline Visibility - Business school ranking (R) & average [range] & $59.1[1 ; 101]$ \\
\hline Visibility - Centrality (R) & average [range] & $6.0[4 ; 12,4]$ \\
\hline Visibility - U.S. affiliation & average [range] & $0.8[0 ; 1]$ \\
\hline Visibility - Number of authors & average [range] & $2.2[1 ; 7]$ \\
\hline Personal Promotion - Reference intensity & average [range] & $46.2[0 ; 313]$ \\
\hline Personal Promotion - Self-citation intensity & average [range] & $2.1[0 ; 37]$ \\
\hline \multicolumn{3}{|l|}{ Presentation Perspective } \\
\hline Title length & average [range] & $7.0[1 ; 20]$ \\
\hline Attention Grabbers - Marketing & count & 177 \\
\hline Attention Grabbers - Market & count & 157 \\
\hline Attention Grabbers - New & count & 99 \\
\hline Attention Grabbers - Number of keywords & average [range] & $6.1[1 ; 12]$ \\
\hline Expositional Clarity - Number of equations & average [range] & $4.0[0 ; 57]$ \\
\hline Expositional Clarity - Number of figures & average [range] & $2.0[0 ; 18]$ \\
\hline Expositional Clarity - Number of tables & average [range] & $3.3[0 ; 29]$ \\
\hline Expositional Clarity - Number of footnotes & average [range] & $5.9[0 ; 38]$ \\
\hline Expositional Clarity - Number of appendices & average [range] & $0.6[0 ; 41]$ \\
\hline Expositional Clarity - Reading ease & average [range] & $22.9[0 ; 58]$ \\
\hline Number of Observations & & 1,825 \\
\hline
\end{tabular}


Table 3:

Estimation Results for Equation (2)

\begin{tabular}{|c|c|c|c|c|c|c|c|c|}
\hline \multirow[b]{2}{*}{ Variable } & \multicolumn{2}{|c|}{ Nested Model 1} & \multicolumn{2}{|c|}{ Nested Model 2} & \multicolumn{2}{|c|}{ Nested Model 3} & \multicolumn{2}{|c|}{ Full Model } \\
\hline & Coeff & $\begin{array}{l}\text { Std } \\
\text { Err }\end{array}$ & Coeff & $\begin{array}{l}\text { Std } \\
\text { Err }\end{array}$ & Coeff & $\begin{array}{l}\text { Std } \\
\text { Err }\end{array}$ & Coeff & $\begin{array}{l}\text { Std } \\
\text { Err }\end{array}$ \\
\hline \multicolumn{9}{|l|}{ Universalist Perspective } \\
\hline Quality - Article order (R) & $-0.02 * * *$ & 0.01 & & & & & $-0.02 * *$ & 0.01 \\
\hline Quality - Awards & $0.53^{* * *}$ & 0.08 & & & & & $0.34^{* * *}$ & 0.08 \\
\hline Quality - Article length & $0.05^{* * *}$ & 0.00 & & & & & $0.04 * * *$ & 0.01 \\
\hline \multicolumn{9}{|l|}{ Domain } \\
\hline Orientation - Behavioral & -0.01 & 0.06 & & & & & 0.04 & 0.05 \\
\hline Orientation - Quantitative & -0.02 & 0.07 & & & & & 0.03 & 0.07 \\
\hline Method Type - Conceptual & 0.00 & 0.05 & & & & & -0.02 & 0.04 \\
\hline Method Type - Empirical & -0.00 & 0.06 & & & & & -0.04 & 0.06 \\
\hline Method Type - Methodological & $-0.24 * * *$ & 0.08 & & & & & -0.11 & 0.09 \\
\hline Method Type - Analytical & $-0.41^{* * *}$ & 0.08 & & & & & -0.13 & 0.09 \\
\hline Subject Area - New Products & 0.00 & 0.08 & & & & & 0.05 & 0.09 \\
\hline Subject Area - B2B & 0.09 & 0.08 & & & & & 0.09 & 0.08 \\
\hline Subject Area - Relationship & $0.61^{* * *}$ & 0.10 & & & & & $0.55^{* * *}$ & 0.09 \\
\hline Subject Area - Brand and Product & -0.06 & 0.06 & & & & & 0.07 & 0.06 \\
\hline Subject Area - Advertising & $-0.32 * * *$ & 0.06 & & & & & $-0.28 * * *$ & 0.06 \\
\hline Subject Area - Pricing & -0.04 & 0.08 & & & & & 0.02 & 0.08 \\
\hline Subject Area - Promotions & -0.06 & 0.10 & & & & & -0.03 & 0.10 \\
\hline Subject Area - Retailing & -0.07 & 0.09 & & & & & 0.05 & 0.09 \\
\hline Subject Area - Strategy & -0.05 & 0.07 & & & & & -0.05 & 0.07 \\
\hline Subject Area - Sales & $-0.37 * * *$ & 0.10 & & & & & $-0.32 * * *$ & 0.09 \\
\hline Subject Area - Methodology & -0.03 & 0.09 & & & & & -0.01 & 0.09 \\
\hline Subject Area - Services & $0.47^{* * *}$ & 0.11 & & & & & $0.53^{* * *}$ & 0.10 \\
\hline Subject Area - Consumer Knowledge & -0.10 & 0.07 & & & & & $-0.14^{* *}$ & 0.06 \\
\hline Subject Area - Consumer Emotions & -0.02 & 0.07 & & & & & -0.03 & 0.07 \\
\hline Subject Area - Other Consumer Behavior & 0.01 & 0.10 & & & & & 0.03 & 0.10 \\
\hline Subject Area - Consumption Behavior & -0.03 & 0.08 & & & & & 0.05 & 0.08 \\
\hline Subject Area - International Marketing & $0.27^{* *}$ & 0.13 & & & & & 0.05 & 0.11 \\
\hline Subject Area - Other & $-0.32 * * *$ & 0.09 & & & & & $-0.23 * *$ & 0.09 \\
\hline Subject Area - E-Commerce & $0.74^{* * *}$ & 0.17 & & & & & $0.77^{* * *}$ & 0.17 \\
\hline \multicolumn{9}{|l|}{ Social Constructivist Perspective } \\
\hline Visibility - Publication record & & & 0.00 & 0.00 & & & $0.00^{*}$ & 0.00 \\
\hline Visibility - Editorial board membership & & & $0.14^{* * *}$ & 0.05 & & & $0.14^{* * *}$ & 0.04 \\
\hline Visibility - Business school ranking (R) & & & $-0.00 * * *$ & 0.00 & & & $-0.00 * * *$ & 0.00 \\
\hline Visibility - Centrality (R) & & & $0.10^{* *}$ & 0.04 & & & $0.10^{* *}$ & 0.04 \\
\hline Visibility - U.S. affiliation & & & $0.16^{* *}$ & 0.08 & & & 0.00 & 0.07 \\
\hline Visibility - Number of authors & & & -0.01 & 0.03 & & & $-0.06 * *$ & 0.02 \\
\hline Personal Promotion - Reference intensity & & & $0.01^{* * *}$ & 0.00 & & & 0.00 & 0.00 \\
\hline Personal Promotion - Self-citation intensity & & & $0.10^{* * *}$ & 0.01 & & & $0.08^{* * *}$ & 0.01 \\
\hline \multicolumn{9}{|l|}{ Presentation Perspective } \\
\hline Title length & & & & & $-0.02 *$ & 0.01 & -0.01 & 0.01 \\
\hline Attention Grabbers - Marketing & & & & & -0.04 & 0.09 & -0.19 & 0.07 \\
\hline Attention Grabbers - Market & & & & & 0.15 & 0.09 & $0.14^{*}$ & 0.08 \\
\hline Attention Grabbers - New & & & & & 0.05 & 0.09 & 0.10 & 0.09 \\
\hline Attention Grabbers - Number of keywords & & & & & $0.04^{* * *}$ & 0.01 & 0.00 & 0.00 \\
\hline Expositional Clarity - Number of equations & & & & & $-0.01^{* *}$ & 0.00 & $-0.01 * *$ & 0.00 \\
\hline Expositional Clarity - Number of figures & & & & & $0.03^{* * *}$ & 0.01 & 0.00 & 0.01 \\
\hline Expositional Clarity - Number of tables & & & & & 0.02 & 0.01 & -0.00 & 0.01 \\
\hline Expositional Clarity - Number of footnotes & & & & & $0.01^{* *}$ & 0.00 & 0.00 & 0.00 \\
\hline
\end{tabular}




\begin{tabular}{|c|c|c|c|c|c|c|c|c|}
\hline Expositional Clarity - Number of appendices & & & & & -0.00 & 0.01 & $0.00^{* * *}$ & 0.01 \\
\hline Expositional Clarity - Reading ease & & & & & $-0.01 * * *$ & 0.00 & $-0.02 * * *$ & 0.00 \\
\hline \multicolumn{9}{|l|}{ Other Variables } \\
\hline Intercept & $-0.60 * *$ & 0.27 & $-0.67 *$ & 0.40 & 0.31 & 0.35 & $-0.73^{*}$ & 0.44 \\
\hline JCR & $0.80^{* *}$ & 0.32 & 0.09 & 0.31 & 0.13 & 0.38 & $0.72 * *$ & 0.36 \\
\hline $\mathrm{JM}$ & -0.13 & 0.36 & -0.30 & 0.37 & $-0.83^{*}$ & 0.42 & -0.26 & 0.39 \\
\hline JMR & 0.46 & 0.36 & -0.06 & 0.34 & -0.18 & 0.40 & 0.63 & 0.39 \\
\hline IJRM & $-3.59 * * *$ & 1.08 & $-3.95 * * *$ & 1.02 & $-3.68 * * *$ & 1.21 & $-3.34 * * *$ & 1.07 \\
\hline Q*JCR & $0.09 * * *$ & 0.01 & $0.09 * * *$ & 0.01 & $0.11^{* * *}$ & 0.02 & $0.09 * * *$ & 0.01 \\
\hline $\mathrm{Q}^{*} \mathrm{JM}$ & $0.15^{* * *}$ & 0.02 & $0.14^{* * *}$ & 0.02 & $0.19 * * *$ & 0.02 & $0.17 * * *$ & 0.02 \\
\hline Q*JMR & $0.12^{* * *}$ & 0.01 & $0.10^{* * *}$ & 0.01 & $0.12^{* * *}$ & 0.02 & $0.10^{* * *}$ & 0.02 \\
\hline Q*IJRM & $0.40 * * *$ & 0.10 & $0.40^{* * *}$ & 0.10 & $0.37 * * *$ & 0.12 & $0.38 * * *$ & 0.11 \\
\hline Q*MKS & $0.13^{* * *}$ & 0.02 & $0.10^{* * *}$ & 0.02 & $0.12^{* * *}$ & 0.02 & $0.14^{* * *}$ & 0.02 \\
\hline $\mathrm{Q}^{2 *} \mathrm{JCR}$ & $-0.00 * * *$ & 0.00 & $-0.00 * * *$ & 0.00 & $-0.00 * * *$ & 0.00 & $-0.00 * * *$ & 0.00 \\
\hline $\mathrm{Q}^{2 * J M}$ & $-0.00 * * *$ & 0.00 & $-0.00 * * *$ & 0.00 & $-0.00 * * *$ & 0.00 & $-0.00 * * *$ & 0.00 \\
\hline $\mathrm{Q}^{2 *} \mathrm{JMR}$ & $-0.00 * * *$ & 0.00 & $-0.00 * * *$ & 0.00 & $-0.00 * * *$ & 0.00 & $-0.00 * * *$ & 0.00 \\
\hline $\mathrm{Q}^{2 *} \mathrm{IJRM}$ & $-0.01^{* * *}$ & 0.00 & $-0.01 * * *$ & 0.00 & $-0.01^{* *}$ & 0.00 & $-0.01 * * *$ & 0.00 \\
\hline $\mathrm{Q}^{2 *} \mathrm{MKS}$ & $-0.00 * * *$ & 0.00 & $-0.00 * * *$ & 0.00 & $-0.00 * * *$ & 0.00 & $-0.00 * * *$ & 0.00 \\
\hline \multicolumn{9}{|l|}{ Fit Statistics } \\
\hline Akaike Information Criterion & \multicolumn{2}{|l|}{7.51} & \multicolumn{2}{|l|}{7.58} & \multicolumn{2}{|l|}{7.66} & \multicolumn{2}{|l|}{7.48} \\
\hline Schwarz Information Criterion & \multicolumn{2}{|l|}{7.65} & \multicolumn{2}{|l|}{7.65} & \multicolumn{2}{|l|}{7.75} & \multicolumn{2}{|l|}{7.35} \\
\hline Likelihood Ratio Index & \multicolumn{2}{|l|}{0.128} & \multicolumn{2}{|l|}{0.096} & \multicolumn{2}{|l|}{0.080} & \multicolumn{2}{|l|}{0.241} \\
\hline Number of Observations & \multicolumn{2}{|l|}{1,757} & \multicolumn{2}{|l|}{1,757} & \multicolumn{2}{|l|}{1,531} & \multicolumn{2}{|l|}{1,531} \\
\hline
\end{tabular}

${ }^{*} \mathrm{p}<0.10 ;{ }^{* *} \mathrm{p}<0.05 ; * * * \mathrm{p}<0.01$ (two-sided tests) 


\section{Table 4:}

\section{Overview of Hypotheses, Underlying Theory and Results}

\begin{tabular}{|c|c|c|c|c|}
\hline \multirow[b]{2}{*}{ Theoretical Perspective } & \multicolumn{4}{|c|}{ Effects } \\
\hline & Dimension & Hypothesis & Confirmed? & Underlying Theory \\
\hline \multirow[t]{5}{*}{ Universalism } & Quality & H1a $(+)$ & Yes & Inspiration \\
\hline & Domain & $\mathrm{H} 1 \mathrm{~b}(+/-)$ & Partial & Reliability \\
\hline & & $1010(1 / 2)$ & F dillal & Relevance \\
\hline & & & & Maturation \\
\hline & & & & $\begin{array}{l}\text { Divergence in citation } \\
\text { practices }\end{array}$ \\
\hline \multirow{2}{*}{ Social Constructivism } & Visibility & H2a (+) & Partial & Attention \\
\hline & Personal Promotion & $\mathrm{H} 2 \mathrm{~b}(+)$ & Partial & $\begin{array}{l}\text { Confidence in findings } \\
\text { Attention } \\
\text { Indebtedness }\end{array}$ \\
\hline \multirow[t]{3}{*}{ Presentation } & Title Length & НЗа $(+/-)$ & No & $\begin{array}{l}\text { Information content } \\
\text { Complexity }\end{array}$ \\
\hline & Attention Grabbers & H3b $(+)$ & No & Attention \\
\hline & Expositional Clarity & H3c $(+)$ & Partial, at best & $\begin{array}{l}\text { Accessibility } \\
\text { Ability to promote } \\
\text { content }\end{array}$ \\
\hline
\end{tabular}


Figure 1:

\section{Conceptual Framework}

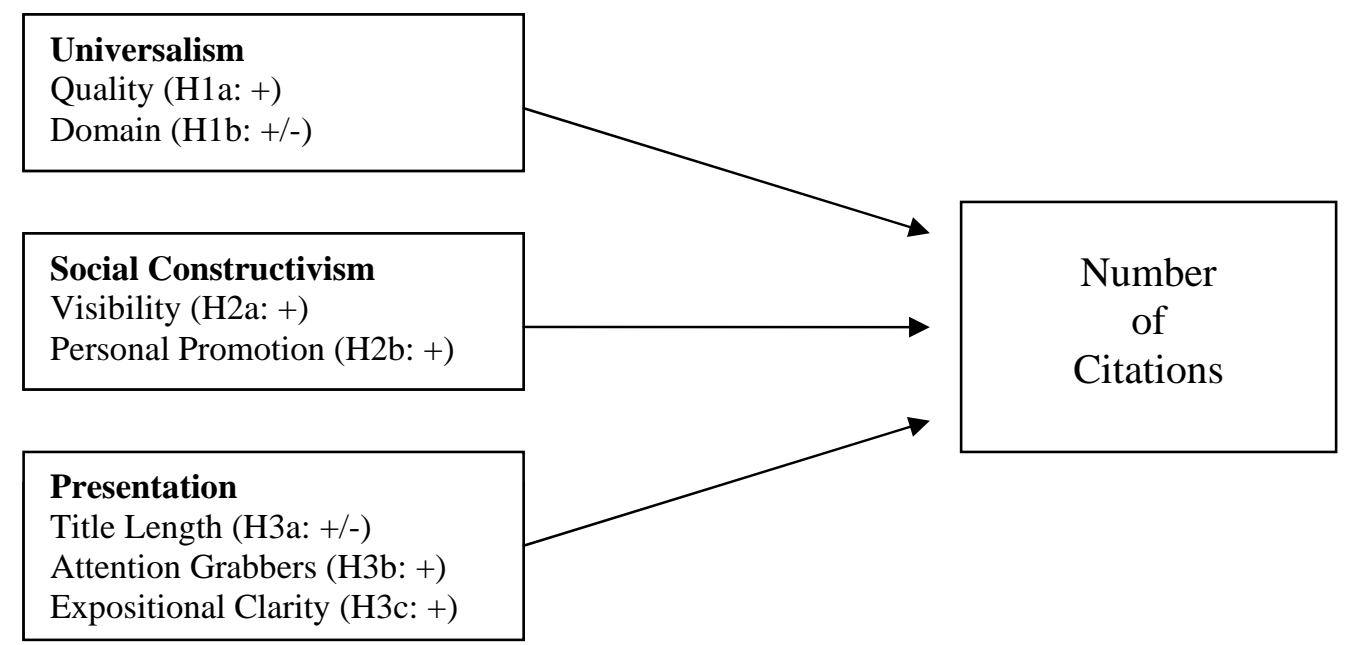


Figure 2:

Median Number of Citations of Articles in Major Marketing Journals

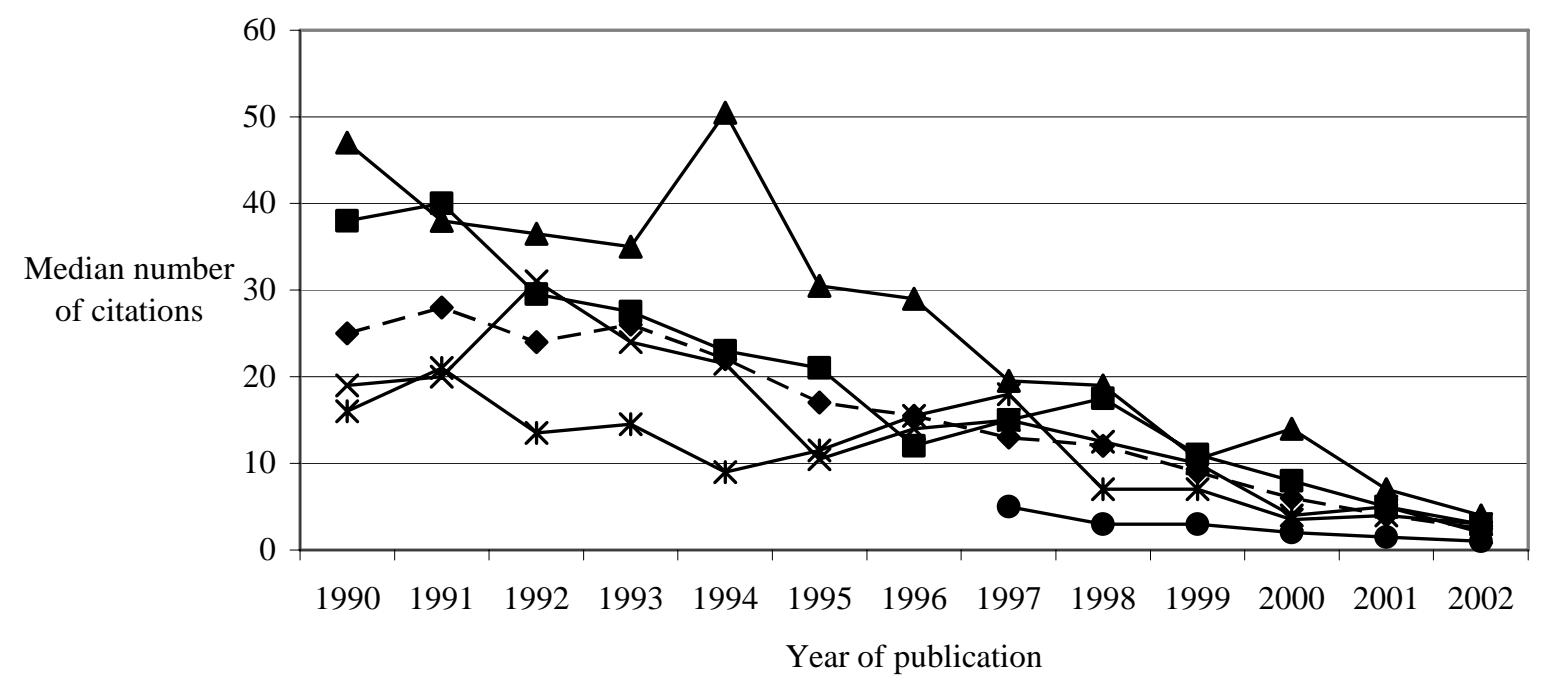

$-\bullet-$ Total sample $\longrightarrow$ JCR $\longrightarrow$ JM $\longrightarrow$ JMR $\longrightarrow$ MKS $\multimap$ IJRM 


\section{References}

Alba, Joseph, John Lynch, Barton Weitz, Chris Janiszewski, Richard Lutz, Alan Sawyer and Stacy Wood (1997), "Interactive Home Shopping: Consumer, Retailer, and Manufacturer Incentives to Participate in Electronic Marketplaces,” Journal of Marketing, 61 (3), 38-53.

Anderson, James C. and James A. Narus (1990), “A Model of Distributor Firm and Manufacturer Firm Working Partnerships,” Journal of Marketing, 54 (1), 42-58.

Armstrong, J. S. (1980), “Unintelligble Management Research and Academic Prestige,” Interfaces, 10 (2), 80-86.

Ayres, Ian and Frederick E. Vars (2000), "Determinants of Citations to Articles in Elite Law Reviews,“Journal of Legal Studies, 29 (1), 427-450.

Baldi, Stephane (1998), "Normative versus Social Constructivist Processes in the Allocation of Citations: A Network-Analytic Model,” American Sociological Review, 63 (6), 829-846.

Bauerly, Ronald J., Don T. Johnson and Mandeep Singh (2005), "Readability and the Impact of Marketing. In: Marketing Renaissance: Opportunities and Imperatives for Improving Marketing Thought, Practice, and Infrastructure,” Journal of Marketing, 69 (October), 19-20.

Baumgartner, Hans and Rik Pieters (2003), "The Structural Influence of Marketing Journals: A Citation Analysis of the Discipline and Its Subareas over Time,” Journal of Marketing, 67 (2), 123139.

Bayer, Alan E. (1982), “A Bibliometric Analysis of Marriage and Family Literature,” Journal of Marriage and the Family, 44 (3), 527-538.

Bergh, Donald D., John Perry and Ralph Hanke (2006), “Some Predictors of SMJ Article Impact," Strategic Management Journal, 27, 81-100.

Bettencourt, Lance A. and Mark B. Houston (2001a), "The Impact of Article Method Type and Subject Area on Article Citations and Reference Diversity in JM, JMR, and JCR,” Marketing Letters, 12 (4), 327-340.

---- and ---- (2001b), "Reference Diversity in JCR, JM and JMR: A Reexamination and Extension of Tellis, Chandy and Ackerman,” Journal of Consumer Research, 28 (September), 313-323.

Bettman James R., Mary Frances Luce and John W. Payne (1998), “Constructive Consumer Choice Processes,” Journal of Consumer Research, 25 (3), 187-217.

Bitner, Mary J. (1990), "Evaluating Service Encounters - The Effects of Physical Surroundings and Employee Responses,” Journal of Marketing, 54 (2), 69-82. 
Bolton, Ruth N. (2003), “From the Editor,” Journal of Marketing, 67 (1), 1-3.

Cameron, A. Colin and Pravin K. Trivedi (1990), "Regression-Based Tests for Overdispersion in the Poisson Model,” Journal of Econometrics, 46 (3), 347-364.

Cialdini, Robert B. (1988), Influence: Science and Practice, Glenview, IL: Scott Foresman and Company.

Cote, Joseph A., Siew Meng Leong and Jane Cote (1991), "Assessing the Influence of Journal of Consumer Research: a Citation Analysis,” Journal of Consumer Research, 18 (3), 402-410.

Cronin, Joseph J. and Steven A. Taylor (1992), "Measuring Service Quality - A Reexamination and Extension,” Journal of Marketing, 56 (3), 55-68.

Day, George S. (1994), “The Capabilities of Market-Driven Organizations,” Journal of Marketing, 58 (4), 37-52.

Doney, Patricia M. and Joseph P. Cannon (1997), "An Examination of the Nature of Trust in BuyerSeller Relationships,” Journal of Marketing, 61 (2), 35-51.

Flesch, R. (1948), “A New Readability Yardstick,” Journal of Applied Psychology, 32 (3), 221-233.

Fournier, Susan (1998), "Consumers and their Brands: Developing Relationship Theory in Consumer Research,” Journal of Consumer Research, 24 (4), 343-373.

Ganesan, Shankar (1994), "Determinants of Long-Term Orientation in Buyer-Seller Relationships,” Journal of Marketing, 58 (2), 1-19.

Garbarino, Ellen and Mark S. Johnson (1999), "The Different Roles of Satisfaction, Trust, and Commitment in Customer Relationships,” Journal of Marketing, 63 (2), 70-87.

Gilbert, Nigel G. (1977), “Referencing as Persuasion,” Social Studies of Science, 7 (1), 112-122.

Goldenberg, Jacob, Barak Libai and Eitan Muller (2005), “An Ego-Centered Analysis of Large-Scale Networks: The Case of the Marketing Discipline,” Working paper.

Hoffman, Donna L. and Morris B. Holbrook (1993), “The Intellectual Structure of Consumer Research - A Bibliometric Study of Author Cocitations in the $1^{\text {st }} 15$ Years of the Journal of Consumer Research,” Journal of Consumer Research, 19 (4), 505-517.

Hoffman, Donna L. and Thomas P. Novak (1996), "Marketing in Hypermedia Computer-Mediated Environments: Conceptual Foundations,” Journal of Marketing, 60 (3), 50-68.

Houston, Franklin S. and Julie B. Gassenheimer (1987), "Marketing and Exchange," Journal of Marketing, 51 (October), 3-18. 
Jacobs, Richard S., Kenneth R. Evans, Robert E. Kleine, III and Timothy D. Landry (2001), "Disclosure and its Reciprocity as Predictors of Key Outcomes of an Initial Sales Encounter," Journal of Personal Selling and Sales Management, 21 (1), 51-61.

Jaworski, Bernard J. and Ajay K. Kohli (1993), "Market Orientation - Antecedents and Consequences,” Journal of Marketing, 57 (3), 53-70.

Kassarjian, Harold (1977), “Content Analysis in Consumer Research,” Journal of Consumer Research, 4 (June), 8-18.

Kerin, Roger A. (1996), "In Pursuit of an Ideal: The Editorial and Literary History of the Journal of Marketing," Journal of Marketing, 60 (1), 1-13.

King, J. (1987), "A Review of Bibliometric and Other Science Indicators and Their Role in Research Evaluation,” Journal of Information Science, 13 (5), 261-276.

Kohli, Ajay K. and Bernard J. Jaworski (1990), "Market Orientation - The Construct, Research Propositions, and Managerial Implications," Journal of Marketing, 54 (2), 1-18.

Landes, William M. and Richard A. Posner (1996), "Heavily Cited Articles in Law," Chicago Kent Law Review, 71, 825-840.

Leong, Siew Meng (1989), “A Citation Analysis of the Journal of Consumer Research,” Journal of Consumer Research, 15 (4), 492-497.

Lynch, John G. and Dan Ariely (2000), "Wine Online: Search Costs Affect Competition on Price, Quality, and Distribution,” Marketing Science, 19 (1), 83-103.

McAlister, Leigh (2005), "Unleashing Potential. In: Marketing Renaissance: Opportunities and Imperatives for Improving Marketing Thought, Practice, and Infrastructure," Journal of Marketing, 69 (October), 16-17.

Merton, Robert K. (1968), “The Matthew effect in science,” Science, 159 (3810), 56-63.

Metoyer-Duran, Cheryl (1993), "The Readability of Published, Accepted, and Rejected Papers Appearing in College and Research Libraries,” College and Research Libraries, 64 (November), 517-526.

Mick, D.G. (2005), “Inklings: From Mind to Page in Consumer Research,” Association of Consumer Research Newsletter, 2005 (Summer), 1-3.

Muniz, Albert M. and Thomas C. O’Guinn (2001), “Brand Community,” Journal of Consumer Research, 27 (4), 412-432.

Narver, John C. and Stanley F. Slater (1990), "The Effect of a Market Orientation Business Profitability,” Journal of Marketing, 54 (4), 20-35. 
Novak, Thomas P., Donna L. Hoffman and Y F. Yung (2000), "Measuring the Customer Experience in Online Environments: A Structural Modeling Approach,” Marketing Science, 19 (1), 22-42.

Peters, H.P.F. and Anthony F.J. van Raan (1994), "On Determinants of Citation Scores: a Case Study in Chemical Engineering,” Journal of the American Society for Information Science, 45 (1), 39-49.

Pieters, Rik, Hans Baumgartner, Jeroen Vermunt and Tammo Bijmolt (1999), "Importance and Similarity in the Evolving Citation Network of the International Journal of Research in Marketing," International Journal of Research in Marketing, 16 (2), 113-127.

Pieters, Rik and Hans Baumgartner (2002), "Who Talks to Whom? Intra- and Interdisciplinary Communication of Economics Journals,” Journal of Economic Literature, 40 (2), 483-509.

Slater, Stanley F. and John C. Narver (1995), "Market Orientation and the Learning Organization,” Journal of Marketing, 59 (3), 63-74.

Smart, Scott and Joel Waldfogel (1996), "A Citation-Based Test for Discrimination at Economics and Finance Journals,” NBER working paper, no. 5460, Cambridge, MA.

Staelin, Richard (2002), “A prior editor’s guidelines on readibablity,” (accessed December 20, 2005), [available at http:/bear.cba.ufl.edu.centers/MKS/author_information/readability.pdf].

Sternberg, Robert J. and Tamara Gordeeva (1996), "The Anatomy of Impact: What Makes an Article Influential?” Psychological Science, 7 (2), 69-75.

Stewart, John A. (1983), "Achievement and Ascriptive Processes in the Recognition of Scientific Articles,” Social Forces, 62 (1), 166-189.

Stremersch, Stefan and Peter C. Verhoef (2005), "Globalization of Authorship in the Marketing Discipline: Does it Help or Hinder the Field?” Marketing Science, 24 (4), 585-594.

Tellis, Gerard J., Rajesh K. Chandy and David S. Ackerman (1999), "In Search of Diversity: The Record of Major Marketing Journals," Journal of Marketing Research, 36 (1), 120-131.

Van Dalen, Hendrik P. and Kène Henkens (2001), "What Makes a Scientific Article Influential? The Case of Demographers," Scientometrics, 50 (3), 455-482.

---- and ---- (2004), "Signals in Science - On the Importance of Signaling in Gaining Attention in Science," Tinbergen discussion paper, Erasmus University Rotterdam.

Van Dalen, Hendrik P. and Arjo Klamer (2005), “Is There Such a Thing Called Scientific Waste?” Tinbergen discussion paper, Erasmus University Rotterdam.

Vargo, Stephen L. and Robert F. Lush (2004), “Evolving to a New Dominant Logic for Marketing,” Journal of Marketing, 68 (1), 1-17 
Webster, Frederick E. (1992), “The Changing Role of Marketing in the Corporation,” Journal of Marketing, 56 (4), 1-17.

Yitzhaki, Moshe (2002), "Relation of the Title Length of a Journal Article to the Length of the Article,” Scientometrics, 54 (3), 435-447.

Zeithaml, Valerie A., Leonard L. Berry and A. Parasuraman (1996), “The Behavioural Consequences of Service Quality," Journal of Marketing, 60 (2), 31-46.

Zinkhan, George M., Martin S. Roth and Mary Jane Saxton (1992), Knowledge Development and Scientific Status in Consumer-Behavior Research - a Social-Exchange Perspective,” Journal of Consumer Research, 19 (2), 282-291. 


\section{Appendix A: Measurement of Variables}

\begin{tabular}{|c|c|c|c|}
\hline Variable & Symbol & Definition & Measurement Description \\
\hline \multicolumn{4}{|l|}{ Dependent Variable } \\
\hline Citation & CITE & Number of citations the article has received. & $\begin{array}{l}\text { Count of the number of citations the article has received } \\
\text { until end of December 2004, from journals in the ISI- } \\
\text { SSCI. }\end{array}$ \\
\hline \multicolumn{4}{|l|}{ Universalism } \\
\hline \multicolumn{4}{|l|}{ Quality } \\
\hline - Article Order (R) & U1 & Article order in journal issues. & $\begin{array}{l}1 \text { (lead article in journal issues) ... } \mathrm{n} \text { (last article in } \\
\text { journal issues). }\end{array}$ \\
\hline - Awards & $\mathrm{U} 2$ & Whether the article received a best paper award. & $\begin{array}{l}\text { Dummy: } 0 \text { (if the article did not win a best paper award) } \\
\text { or } 1 \text { (if the article won a best paper award), based on Best } \\
\text { article awards at JCR and IJRM, Harold D. Maynard and } \\
\text { MSI/H. Paul Root Award at JM, Paul Green and O'Dell } \\
\text { Award at JMR and J.D.C. Little Award at MKS. }\end{array}$ \\
\hline - Article Length & U3 & Length of the article. & Count of the number of pages of the article. \\
\hline \multicolumn{4}{|l|}{ Domain } \\
\hline - Orientation & U4-U5 & The orientation of the article: behavioral or quantitative & $\begin{array}{l}\text { Two dummies: Behavioral and Quantitative }(0=\text { does not } \\
\text { belong to orientation, } 1=\text { belongs to orientation }) \text {. An } \\
\text { article may cover multiple orientations. }\end{array}$ \\
\hline - Method Type & U6-U9 & $\begin{array}{l}\text { Type of method the article uses: conceptual, empirical, } \\
\text { methodological and analytical (Tellis, Chandy and } \\
\text { Ackerman 1999). }\end{array}$ & $\begin{array}{l}\text { Four dummies: Conceptual, Empirical, Methodological } \\
\text { and Analytical ( } 0=\text { does not belong to method type, } 1= \\
\text { belongs to method type). An article may cover multiple } \\
\text { method types. }\end{array}$ \\
\hline - Subject Area & $\begin{array}{l}\text { U10- } \\
\text { U28 }\end{array}$ & Subject area that the article covers. & $\begin{array}{l}19 \text { dummy variables indicating whether article covers } \\
\text { subject area ( } 0=\text { no coverage; } 1=\text { coverage). An article } \\
\text { may cover multiple subject areas. }\end{array}$ \\
\hline \multicolumn{4}{|l|}{ Social Constructivism } \\
\hline \multicolumn{4}{|l|}{ Visibility } \\
\hline - Publication Record & $\mathrm{C} 1$ & $\begin{array}{l}\text { The publication productivity of all authors in the } \\
\text { considered } 5 \text { journals. }\end{array}$ & $\begin{array}{l}\text { Summation of the number of prior publications of all } \\
\text { authors before the article appeared in the } 5 \text { journals we } \\
\text { consider. }\end{array}$ \\
\hline $\begin{array}{l}\text { - Editorial Board } \\
\text { Membership }\end{array}$ & $\mathrm{C} 2$ & $\begin{array}{l}\text { Whether there is a connection between the authors of a } \\
\text { paper and an editorial board. }\end{array}$ & $\begin{array}{l}\text { Dummy indicating whether at least one of the authors of } \\
\text { a paper has been a member of the editorial board of JCR, } \\
\text { JM, JMR, MKS or IJRM between the year of publication } \\
\text { of the paper and } 2 \text { years after publication ( } 0 \text { if this is not } \\
\text { the case, } 1 \text { if this is the case). }\end{array}$ \\
\hline
\end{tabular}




\begin{tabular}{|c|c|c|c|}
\hline Variable & Symbol & Definition & Measurement Description \\
\hline $\begin{array}{l}\text { - Business School } \\
\text { Ranking (R) }\end{array}$ & C3 & $\begin{array}{l}\text { The Financial Times Business school ranking of all } \\
\text { authors of the article. }\end{array}$ & $\begin{array}{l}\text { The average Business school ranking of all the authors of } \\
\text { an article (based on the B-School ranking of Financial } \\
\text { Times in 2004). }\end{array}$ \\
\hline - Centrality (R) & $\mathrm{C} 4$ & $\begin{array}{l}\text { The degree to which the author team is connected to other } \\
\text { researchers in the discipline. }\end{array}$ & $\begin{array}{l}\text { The minimum across the authors on the paper of their } \\
\text { individual centrality in the discipline. In order to } \\
\text { calculate individual centrality of a researcher, one has to } \\
\text { find the shortest route of this researcher to all other } \\
\text { researchers (based on co-author relationships) and then } \\
\text { compute the average across all these paths. }\end{array}$ \\
\hline - U.S. Affiliation & $\mathrm{C} 5$ & $\begin{array}{l}\text { Affiliation of the authors to U.S. universities or } \\
\text { institutions. }\end{array}$ & $\begin{array}{l}\text { Share of all authors of the article having a U.S.- } \\
\text { affiliation. }\end{array}$ \\
\hline - Number of Authors & C6 & Number of authors of the article. & Count of the number of authors of the article. \\
\hline \multicolumn{4}{|l|}{ Personal Promotion } \\
\hline - Reference Intensity & $\mathrm{C} 7$ & Number of references in the article. & $\begin{array}{l}\text { Count of the number of references in the reference list of } \\
\text { the article. }\end{array}$ \\
\hline - Self-citation Intensity & $\mathrm{C} 8$ & $\begin{array}{l}\text { Intensity with which authors of the article cite their own } \\
\text { prior work. }\end{array}$ & $\begin{array}{l}\text { Count of the number of self-citations by all authors of the } \\
\text { article until December 31, } 2004 \text {. }\end{array}$ \\
\hline \multicolumn{4}{|l|}{ Presentation } \\
\hline \multicolumn{4}{|l|}{ Title Length } \\
\hline Title Length & P1 & Length of the title of the article. & $\begin{array}{l}\text { Count of the number of significant words in the title of } \\
\text { article. }\end{array}$ \\
\hline \multicolumn{4}{|l|}{ Attention Grabbers } \\
\hline • “Marketing” in Title & P2 & The presence of the word "Marketing" in the title. & $\begin{array}{l}\text { Dummy indicating whether the word "marketing" is } \\
\text { present in the title of the article ( } 0=\text { not present, } \\
1=\text { =resent). }\end{array}$ \\
\hline • "Market" in Title & P3 & The presence of the word "Market" in the title. & $\begin{array}{l}\text { Dummy indicating whether the word "market" is present } \\
\text { in the title of the article ( } 0=\text { not present, } 1=\text { present). }\end{array}$ \\
\hline - "New" in Title & P4 & The presence of the word "New" in the title. & $\begin{array}{l}\text { Dummy indicating whether the word "new" is present in } \\
\text { the title of the article ( } 0=\text { not present, } 1=\text { =present). }\end{array}$ \\
\hline - Number of Keywords & P5 & The number of keywords for the article. & Count of the number of keywords as assigned by ISI. \\
\hline Expositional Clarity & & & \\
\hline
\end{tabular}


- Number of Equations

- Number of Figures

- Number of Tables

- Number of Footnotes

- Number of Appendices

- Reading Ease \begin{tabular}{|l|l} 
P6 & Number of equations in the article.
\end{tabular}

Number of figures in the article.

Number of tables in the article.

Number of footnotes in the article.

Number of appendices in the article.

P11

Flesch reading ease score.
Count of the number of tables in the article.

Count of the number of footnotes in the article.

Count of the number of appendices in the article.

The Flesch reading ease score is obtained by the formula: $206.835-(.846 *$ [number of syllables per 100 words] $)-$ (1.015* [average number of words per sentence]).

The text is easier to understand as the score is higher. 


\section{Appendix B:}

\section{Sample Descriptives over Time of Independent Variables}

\begin{tabular}{|c|c|c|c|c|c|c|c|c|}
\hline & Symbol & $\begin{array}{c}2001 \\
- \\
2002 \\
\end{array}$ & $\begin{array}{c}1999 \\
- \\
2000 \\
\end{array}$ & $\begin{array}{c}1997 \\
- \\
1998 \\
\end{array}$ & $\begin{array}{c}1995 \\
- \\
1996 \\
\end{array}$ & $\begin{array}{c}1993 \\
- \\
1994 \\
\end{array}$ & $\begin{array}{c}1991 \\
- \\
1992 \\
\end{array}$ & 1990 \\
\hline \multicolumn{9}{|l|}{ Universalist Perspective } \\
\hline Quality - Article order (R) & u1 & 5.0 & 4.7 & 4.3 & 5.5 & 5.4 & 5.1 & 5.1 \\
\hline Quality - Awards & u2 & 0.03 & 0.04 & 0.04 & 0.04 & 0.03 & 0.03 & 0.02 \\
\hline Quality - Article length & u3 & 14.9 & 15.5 & 14.9 & 13.9 & 14.7 & 13.2 & 12.5 \\
\hline \multicolumn{9}{|l|}{ Domain } \\
\hline Orientation - Behavioral & u4 & 204.0 & 165.0 & 186.0 & 157.0 & 204.0 & 177.0 & 97.0 \\
\hline Orientation - Quantitative & u5 & 83.0 & 77.0 & 76.0 & 85.0 & 54.0 & 77.0 & 31.0 \\
\hline Method Type - Conceptual & u6 & 137.0 & 125.0 & 129.0 & 95.0 & 110.0 & 96.0 & 62.0 \\
\hline Method Type - Empirical & u7 & 230.0 & 226.0 & 240.0 & 203.0 & 215.0 & 204.0 & 102.0 \\
\hline Method Type - Methodological & u8 & 53.0 & 48.0 & 50.0 & 66.0 & 45.0 & 55.0 & 25.0 \\
\hline Method Type - Analytical & u9 & 53.0 & 42.0 & 48.0 & 41.0 & 50.0 & 42.0 & 21.0 \\
\hline Subject Area - New Products & u10 & 18.0 & 24.0 & 36.0 & 18.0 & 13.0 & 14.0 & 9.0 \\
\hline Subject Area - B2B & u11 & 25.0 & 36.0 & 34.0 & 26.0 & 29.0 & 26.0 & 10.0 \\
\hline Subject Area - Relationship & u12 & 15.0 & 19.0 & 22.0 & 8.0 & 15.0 & 11.0 & 1.0 \\
\hline Subject Area - Brand and Product & u13 & 62.0 & 42.0 & 43.0 & 41.0 & 52.0 & 40.0 & 23.0 \\
\hline Subject Area - Advertising & u14 & 25.0 & 28.0 & 29.0 & 31.0 & 42.0 & 36.0 & 27.0 \\
\hline Subject Area - Pricing & u15 & 28.0 & 25.0 & 18.0 & 22.0 & 13.0 & 21.0 & 5.0 \\
\hline Subject Area - Promotions & u16 & 15.0 & 7.0 & 10.0 & 18.0 & 8.0 & 8.0 & 9.0 \\
\hline Subject Area - Retailing & u17 & 16.0 & 10.0 & 18.0 & 11.0 & 5.0 & 8.0 & 4.0 \\
\hline Subject Area - Strategy & u18 & 39.0 & 30.0 & 43.0 & 41.0 & 33.0 & 31.0 & 11.0 \\
\hline Subject Area - Sales & u19 & 11.0 & 10.0 & 12.0 & 9.0 & 20.0 & 9.0 & 7.0 \\
\hline Subject Area - Methodology & u20 & 42.0 & 43.0 & 27.0 & 39.0 & 32.0 & 47.0 & 25.0 \\
\hline Subject Area - Services & u21 & 8.0 & 8.0 & 11.0 & 9.0 & 13.0 & 9.0 & 3.0 \\
\hline Subject Area - Consumer Knowledge & u22 & 40.0 & 31.0 & 28.0 & 32.0 & 35.0 & 40.0 & 19.0 \\
\hline Subject Area - Consumer Emotions & u23 & 29.0 & 24.0 & 20.0 & 17.0 & 22.0 & 21.0 & 10.0 \\
\hline Subject Area - Other Consumer Behavior & u24 & 9.0 & 7.0 & 14.0 & 10.0 & 23.0 & 22.0 & 7.0 \\
\hline Subject Area - Consumption Behavior & u25 & 21.00 & 15.0 & 22.0 & 16.0 & 27.0 & 29.0 & 15.0 \\
\hline Subject Area - International Marketing & u26 & 10.0 & 14.0 & 11.0 & 3.0 & 10.0 & 4.0 & 2.0 \\
\hline Subject Area - Other & u27 & 19.0 & 14.0 & 11.0 & 11.0 & 15.0 & 13.0 & 4.0 \\
\hline Subject Area - E-commerce & u28 & 11.0 & 12.0 & 2.0 & 2.0 & 1.0 & 0.0 & 0.0 \\
\hline \multicolumn{9}{|l|}{ Social Constructivist Perspective } \\
\hline Visibility - Publication record & $\mathrm{c} 1$ & 11.8 & 11.9 & 10.9 & 11.9 & 10.0 & 8.6 & 9.2 \\
\hline Visibility - Editorial board membership & c2 & 0.7 & 0.6 & 0.5 & 0.7 & 0.6 & 0.6 & 0.5 \\
\hline
\end{tabular}


Visibility - Business school ranking (R)

Visibility - Centrality (R)

Visibility - U.S. affiliation

Visibility - Number of authors

Personal Promotion - Reference intensity

Personal Promotion - Self-citation intensity

Presentation Perspective

Title length

Attention Grabbers - Marketing

Attention Grabbers - Market

Attention Grabbers - New

Attention Grabbers - Number of keywords

Expositional Clarity - Number of equations

Expositional Clarity - Number of figures

Expositional Clarity - Number of tables

Expositional Clarity - Number of footnotes

Expositional Clarity - Number of appendices

Expositional Clarity - Reading ease

$\begin{array}{ccccccc}59.8 & 56.2 & 57.9 & 58.3 & 62.8 & 58.8 & 60.2 \\ 6.0 & 6.0 & 5.9 & 5.9 & 6.0 & 5.9 & 6.0 \\ 0.7 & 0.8 & 0.8 & 0.8 & 0.9 & 0.9 & 0.9 \\ 2.2 & 2.3 & 2.3 & 2.2 & 2.2 & 2.0 & 2.0 \\ 47.6 & 50.4 & 46.3 & 44.8 & 48.6 & 42.1 & 39.5 \\ 0.7 & 1.4 & 2.4 & 2.3 & 2.6 & 2.7 & 2.9 \\ & & & & & & \\ 7.5 & 7.2 & 7.0 & 6.8 & 7.0 & 6.9 & 6.8 \\ 28.0 & 39.0 & 25.0 & 21.0 & 25.0 & 25.0 & 14.0 \\ 34.0 & 29.0 & 18.0 & 28.0 & 21.0 & 18.0 & 9.0 \\ 17.0 & 20.0 & 26.0 & 14.0 & 9.0 & 6.0 & 5.0 \\ 6.9 & 6.7 & 6.1 & 5.7 & 5.9 & 5.2 & 6.1 \\ 3.9 & 3.9 & 4.3 & 5.0 & 3.3 & 3.8 & 3.8 \\ 2.1 & 2.2 & 2.1 & 2.0 & 1.9 & 2.0 & 1.5 \\ 3.1 & 3.7 & 3.8 & 3.3 & 3.3 & 3.0 & 2.7 \\ 5.2 & 7.1 & 6.2 & 5.9 & 6.1 & 5.2 & 5.0 \\ 0.6 & 0.5 & 0.6 & 0.8 & 0.6 & 0.5 & 0.3 \\ 22.5 & 22.4 & 23.1 & 23.6 & 22.6 & 23.3 & 23.1 \\ & & & & & & \\ \mathbf{3 0 8} & \mathbf{2 8 3} & \mathbf{2 9 3} & \mathbf{2 6 2} & \mathbf{2 8 3} & \mathbf{2 6 1} & \mathbf{1 3 5}\end{array}$


Appendix C: Correlation Matrix

\begin{tabular}{|c|c|c|c|c|c|c|c|c|c|c|c|c|c|c|c|c|c|c|c|c|c|c|c|c|}
\hline & ITE & U1 & U2 & U3 & $\mathrm{U} 4$ & U5 & U6 & $\mathrm{U} 7$ & U8 & U9 & U10 & U11 & U12 & U13 & U14 & U15 & U16 & U17 & U18 & U19 & U20 & U21 & U22 & U23 \\
\hline CITE & 1.00 & -0.12 & 0.18 & 0.08 & 0.10 & -0.12 & 0.12 & 0.00 & -0.10 & -0.09 & -0.01 & 0.10 & 0.16 & 206 & -0.04 & 0.06 & -0.05 & -0.04 & 0.01 & -0.02 & -0.07 & 0.19 & 804 & 0.02 \\
\hline U1 & -0.12 & 1.00 & -0.17 & 40 & 01 & 0.04 & -0.05 & -0.02 & 0.08 & -0.09 & 0.00 & -0.09 & -0.04 & . 00 & 0.02 & .04 & 0.02 & 3 & -0.05 & 0.00 & 0.12 & -0.02 & .01 & 01 \\
\hline 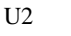 & 0.18 & -0.17 & 1.00 & 0.16 & -0.05 & 0.01 & 02 & -0.09 & 0.00 & 0.02 & 0.05 & 0.04 & 0.00 & 0.03 & 0.00 & 0.02 & 0.00 & .00 & 0.05 & -0.03 & -0.06 & 0.01 & .01 & 0.04 \\
\hline U3 & 0.08 & .40 & 0.16 & 1.00 & -0.02 & 0.09 & 0.09 & 0.00 & -0.09 & 0.18 & 0.01 & 0.12 & 0.08 & 0.00 & -0.06 & .05 & .01 & 9 & 0.09 & 0.03 & -0.11 & 03 & -0.04 & -0.04 \\
\hline 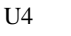 & 0.10 & 01 & -0.05 & -0.02 & 00 & -0.26 & .09 & 0.20 & 0.15 & -0.18 & -0.19 & -0.28 & 0.08 & 13 & 0.13 & -0.02 & 0.01 & -0.02 & -0.32 & 0.03 & -0.10 & 04 & .23 & 0.20 \\
\hline U5 & -0.12 & 04 & 0.01 & 0.09 & -0.26 & 1.00 & -0.38 & -0.12 & 0.48 & 0.43 & 0.03 & -0.03 & -0.06 & م 0 & -0.12 & 0.07 & 0.06 & 0.04 & 0.08 & -0.01 & 0.25 & -0.03 & -0.09 & 0.14 \\
\hline c & 0.12 & 05 & & 0.09 & 0.09 & -0.38 & 00 & -0.04 & -0.37 & -0.30 & 0.04 & 0.06 & 0.05 & -0.07 & 0.00 & -0.06 & -0.07 & -0.03 & -0.01 & 0.05 & -0.22 & .08 & -0.02 & -0.01 \\
\hline U7 & & 02 & -0.09 & 0.00 & 0.20 & -0.12 & -0.04 & 1.00 & 0.00 & -0.21 & 0.04 & -0.06 & 07 & 0.10 & 0.09 & 0.00 & 0.05 & 0.01 & -0.08 & & -0.15 & .03 & 0.08 & 0.09 \\
\hline U8 & 0.10 & 08 & 0.00 & -0.09 & -0.15 & 0.48 & -0.37 & 0.00 & 00 & -0.14 & 0.00 & -0.11 & -0.08 & 0.05 & -0.10 & -0.02 & 0.03 & -0.03 & -0.03 & -0.06 & 0.47 & -0.07 & -0.12 & -0.09 \\
\hline IO & -0.09 & .09 & 02 & 010 & -0.18 & 042 & -0.30 & -0.21 & -0.14 & 1.00 & 0.00 & 0.08 & 0.01 & 0.03 & -0.04 & 0.17 & 0.11 & 0.12 & 0.16 & 0.06 & 0 & 0.02 & 0.04 & -0.08 \\
\hline 010 & -0.01 & 00 & 15 & 0. & -0.19 & 0.03 & 04 & 0.04 & .00 & 0.00 & 1.00 & -0.03 & -0.07 & -0.09 & -0.09 & -0.05 & -0.06 & -0.06 & 0.07 & -0.05 & 0.09 & 0.05 & -0.07 & -0.07 \\
\hline U11 & 0.10 & .09 & 04 & 0.12 & -0.28 & -0.03 & 0.06 & -0.06 & -0.11 & 0.0 & -0.03 & 1.00 & & -0.12 & -0.11 & -0.07 & -0.03 & 0.01 & 0.04 & -0.03 & -0.13 & -0.05 & -0.13 & -0.10 \\
\hline U12 & & 04 & 0 & 0.08 & & -0.06 & & 0.07 & -0.08 & 0.01 & -0.07 & 0.01 & 00 & -0.02 & -0.09 & -0.06 & -0.05 & -0.03 & -0.06 & -0.05 & -0.09 & 0.22 & 09 & -0.04 \\
\hline 13 & -0 & 03 & & & & 0.0 & -0.07 & & & 0.05 & -0.09 & -0.12 & -0.02 & 1. & -0.07 & 0 & $0 . c$ & -0.02 & -0.09 & -0.09 & & -0.01 & & .00 \\
\hline 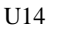 & -0.04 & & 0 & .06 & & -0 . & 0.00 & & -0.10 & -0.04 & -0.09 & -0.11 & & -0 . & & -0. & -0.0 & -0.03 & & -0.04 & & -0.05 & -0.01 & .08 \\
\hline 15 & -0.06 & & -0 & & .02 & $0 . c$ & 0 & & & 0.1 & & -0.0 & & & & 1.8 & & & 0. & -0.04 & & -0.02 & 33 & -0.07 \\
\hline 16 & -0.0 & & & & & & -0.07 & & & & -0 . & -0.0 & & & & & & & & & & 04 & & -0.04 \\
\hline $\mathrm{U}$ & 0 & & & & -0.02 & & 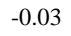 & & & & & & & & & & & & & 02 & & 1 & & 0.06 \\
\hline 18 & 0.01 & & & & -0.32 & & -0.01 & -0 . & -0.03 & & & & & -0.09 & & & & & & & & & & -0.10 \\
\hline & & & & & & & & & & & & & & & & & & & & & & 2 & & 0.04 \\
\hline & -0.0 & & -0.06 & & -0.10 & & -0.22 & & & & -0.8 & -013 & & & & & & -0 & & & & & & 0.07 \\
\hline & & & & & & & & & & & & & & & & & & & & & & & & 0.01 \\
\hline & & & & & & -0.09 & & & & & & & & & & & & & & & & & & .04 \\
\hline $\mathrm{U}$ & -0.0 & & & & & -0. & -0.0 & & -0. & -0 & -0. & 0. & & & & & & 6 & & -0.04 & & 1 & & 1.00 \\
\hline & & & & & & -0. & -0.0 & -0. & & & & & & & & & & & & & & & & 0.06 \\
\hline & & & & & & -0. & & & & & & & & & & & & & & & & & & -0.04 \\
\hline & & & & & & & & & & & & & & & & & & & & & & 1 & & .00 \\
\hline & 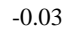 & & & & & -0. & & & & & -0 & & & & & & & & & & & & & 0.06 \\
\hline & & & & & & 0. & & & & & & r & & -0 . & & & & & 0 & & & & & -0.04 \\
\hline & & & & & & & & & & & & & & & & & & & & & & & & 0.00 \\
\hline & & & & & & & & & & & & & & & & & & & & & & 4 & & -0.01 \\
\hline & & & & & & & & & & & & & & & & & & & & & & & & 0.02 \\
\hline $\mathrm{C}$ & -0. & & & & & -0 & & & & & & & & & & & & 1 & -0 & & & & & .04 \\
\hline C & & & & & & & & -0 . & & & & & & & & & & & & & & & & 01 \\
\hline C & & & & & & & & & & & & & & & & & & & & & & & & -0.02 \\
\hline C & & & & & & & & & & & & & & & & & & & & & & & & .01 \\
\hline & & & & & & & & & & & & & & & & & & & & & & & & .01 \\
\hline $\mathrm{P}$ & -0.0 & & -0. & & & & & & & & & & & & & & & & & & & & & .00 \\
\hline & & & & & & & & & & & & & & & & & & & & & & & & .08 \\
\hline$P_{3}^{3}$ & & & & & & & & & & & & & & & & & & & & & & & & .06 \\
\hline & & & & & & & & & & & & & & & & & & & & & & & & -0.07 \\
\hline$P_{s}$ & & & & & & & & & & & & & & & & & & & & & & & & 0.04 \\
\hline & & & & & & & & & & & & & & & & & & & & & & & & 11 \\
\hline $\mathrm{P}$ & & & & & & & & & & & & & & & & & & & & & & & & -0.06 \\
\hline P8 & & & & & & & -0.1 & & & & & & & & & & & & & & & & & -0.03 \\
\hline P9 & & & & & & & & & & & & & & & & & & & & 2 & & & & -0.05 \\
\hline & -0. & & & & & & -0.0 & -0. & 0.0 & & & & & -0. & -0 & & & & & & & & -0.02 & -0.03 \\
\hline P11 & -0.20 & -0.05 & -0.01 & 0.10 & 0.02 & 0.28 & -0.27 & -0.10 & 0.06 & 0.40 & -0.03 & -0.08 & -0.07 & 0.12 & -0.01 & 0.19 & 0.12 & 0.13 & 0.00 & -0.02 & 0.00 & -0.02 & -0.01 & -0.05 \\
\hline
\end{tabular}




\begin{tabular}{|c|c|c|c|c|c|c|c|c|c|c|c|c|c|c|c|c|c|c|c|c|c|c|c|c|}
\hline & U24 & U25 & U26 & U27 & U28 & C1 & $\mathrm{C} 2$ & C3 & $\mathrm{C} 4$ & C5 & C6 & C7 & C8 & P1 & P2 & P3 & P4 & P5 & P6 & P7 & P8 & P9 & P10 & P11 \\
\hline CITE & 0.01 & 0.00 & 0.02 & -0.03 & 0.00 & 0.02 & 0.05 & 0.00 & -0.01 & 0.14 & -0.02 & 0.22 & 0.39 & -0.07 & 0.04 & 0.05 & 0.00 & 0.10 & -0.11 & -0.00 & -0.02 & -0.05 & -0.02 & -0.20 \\
\hline U1 & 0.07 & 0.01 & -0.03 & -0.04 & -0.01 & 0.02 & -0.05 & 0.03 & -0.01 & 0.03 & -0.02 & -0.24 & -0.13 & 0.02 & -0.07 & -0.03 & -0.02 & -0.13 & -0.07 & -0.11 & -0.10 & -0.13 & -0.07 & -0.05 \\
\hline U2 & -0.03 & -0.02 & -0.02 & 0.00 & 0.02 & 0.09 & 0.09 & -0.05 & -0.06 & 0.01 & 0.06 & 0.14 & 0.12 & -0.06 & 0.07 & 0.07 & 0.05 & 0.08 & 0.03 & 0.11 & 0.01 & 0.11 & 0.02 & -0.01 \\
\hline U3 & -0.05 & 0.00 & 0.07 & 0.00 & 0.04 & -0.02 & 0.06 & -0.07 & 0.00 & 0.01 & 0.03 & 0.44 & 0.07 & 0.02 & 0.01 & 0.06 & 0.02 & 0.22 & 0.21 & 0.31 & 0.27 & 0.37 & 0.19 & 0.10 \\
\hline U4 & 0.15 & 0.16 & 0.04 & 0.04 & -0.05 & -0.09 & -0.04 & 0.03 & 0.05 & 0.10 & -0.04 & 0.01 & 0.03 & 0.06 & -0.22 & -0.19 & -0.17 & 0.10 & -0.20 & -0.09 & -0.05 & -0.09 & -0.08 & 0.02 \\
\hline U5 & -0.05 & -0.01 & -0.08 & -0.10 & 0.04 & 0.14 & 0.06 & -0.10 & -0.14 & -0.07 & 0.04 & -0.27 & -0.04 & 0.00 & -0.03 & 0.09 & 0.03 & -0.30 & 0.53 & 0.18 & 0.16 & 0.21 & 0.14 & 0.28 \\
\hline U6 & -0.01 & 0.01 & 0.02 & 0.10 & 0.02 & -0.09 & -0.04 & 0.09 & 0.06 & 0.02 & 0.00 & 0.33 & 0.03 & 0.00 & 0.05 & 0.00 & 0.03 & 0.22 & -0.31 & -0.06 & -0.11 & -0.10 & -0.06 & -0.27 \\
\hline U7 & -0.05 & 0.04 & 0.04 & -0.14 & -0.04 & -0.02 & -0.01 & 0.01 & -0.07 & -0.01 & 0.16 & -0.10 & 0.06 & 0.18 & -0.20 & -0.01 & 0.00 & 0.14 & -0.09 & 0.00 & 0.30 & 0.00 & -0.03 & -0.10 \\
\hline U8 & 0.03 & -0.02 & -0.02 & -0.09 & -0.02 & 0.18 & 0.06 & 0.02 & -0.13 & -0.09 & 0.06 & -0.20 & -0.00 & 0.04 & 0.04 & 0.07 & 0.05 & -0.18 & 0.30 & 0.08 & 0.18 & 0.04 & 0.02 & 0.06 \\
\hline U9 & -0.07 & 0.01 & -0.03 & -0.08 & 0.05 & 0.04 & 0.02 & -0.17 & -0.05 & 0.02 & -0.02 & -0.21 & -0.07 & -0.08 & -0.07 & 0.04 & 0.00 & -0.21 & 0.50 & 0.18 & 0.03 & 0.32 & 0.17 & 0.40 \\
\hline U10 & -0.02 & -0.07 & 0.07 & -0.05 & 0.00 & 0.05 & 0.01 & -0.05 & -0.10 & -0.01 & 0.06 & 0.00 & 0.00 & 0.03 & -0.03 & 0.01 & 0.54 & 0.01 & 0.01 & 0.10 & 0.06 & 0.01 & 0.01 & -0.03 \\
\hline U11 & -0.08 & -0.10 & -0.03 & -0.05 & 0.02 & -0.03 & 0.04 & -0.02 & 0.05 & -0.03 & 0.04 & 0.12 & -0.00 & -0.03 & 0.14 & 0.04 & 0.02 & 0.05 & 0.04 & -0.03 & 0.01 & 0.09 & 0.03 & -0.08 \\
\hline U12 & -0.04 & -0.04 & 0.04 & -0.05 & -0.01 & 0.00 & 0.00 & -0.02 & 0.03 & -0.02 & 0.04 & 0.10 & 0.01 & -0.01 & 0.02 & -0.04 & -0.06 & 0.08 & -0.03 & -0.02 & 0.03 & 0.01 & 0.00 & -0.07 \\
\hline U13 & -0.09 & -0.07 & -0.05 & -0.08 & -0.06 & 0.02 & 0.02 & -0.10 & -0.07 & 0.03 & -0.01 & -0.13 & -0.02 & 0.04 & -0.09 & -0.03 & -0.04 & -0.05 & 0.13 & 0.01 & 0.11 & 0.10 & -0.02 & 0.12 \\
\hline U14 & -0.07 & -0.09 & -0.02 & -0.05 & -0.02 & -0.06 & -0.03 & 0.05 & 0.07 & -0.01 & -0.02 & -0.01 & -0.00 & 0.06 & -0.07 & -0.06 & -0.07 & 0.05 & -0.09 & 0.02 & -0.04 & -0.02 & -0.03 & -0.01 \\
\hline U15 & -0.05 & -0.03 & -0.04 & -0.06 & 0.04 & 0.00 & 0.00 & -0.05 & -0.04 & -0.01 & -0.01 & -0.10 & -0.02 & -0.01 & -0.09 & 0.01 & -0.05 & -0.03 & 0.10 & 0.05 & 0.02 & 0.14 & 0.06 & 0.19 \\
\hline U16 & -0.05 & -0.03 & -0.04 & -0.03 & -0.03 & 0.03 & 0.02 & -0.08 & -0.07 & 0.03 & 0.04 & -0.09 & 0.00 & -0.01 & -0.07 & -0.03 & -0.04 & 0.02 & 0.05 & 0.03 & 0.06 & 0.14 & 0.08 & 0.12 \\
\hline U17 & -0.03 & -0.04 & -0.04 & -0.04 & 0.02 & -0.03 & -0.01 & -0.02 & -0.01 & -0.04 & 0.02 & -0.06 & -0.05 & 0.02 & -0.03 & 0.00 & -0.05 & -0.04 & 0.12 & 0.02 & 0.04 & 0.10 & 0.01 & 0.13 \\
\hline U18 & -0.08 & -0.08 & -0.04 & -0.07 & -0.01 & 0.00 & -0.02 & -0.06 & -0.03 & 0.02 & -0.01 & 0.03 & -0.01 & -0.02 & 0.07 & 0.29 & 0.08 & 0.04 & 0.12 & 0.04 & 0.01 & 0.14 & 0.08 & 0.00 \\
\hline U19 & -0.05 & -0.05 & -0.04 & -0.05 & -0.03 & -0.02 & 0.02 & 0.04 & -0.02 & 0.02 & 0.02 & 0.00 & -0.02 & -0.03 & -0.03 & -0.05 & -0.04 & 0.02 & 0.02 & 0.00 & 0.01 & -0.02 & 0.04 & -0.02 \\
\hline U20 & 0.09 & -0.06 & 0.01 & -0.04 & -0.04 & 0.16 & 0.02 & 0.08 & -0.03 & -0.04 & -0.02 & -0.08 & -0.03 & 0.01 & 0.14 & 0.07 & -0.01 & -0.17 & 0.05 & 0.01 & 0.02 & -0.09 & -0.03 & 0.00 \\
\hline U21 & -0.01 & -0.04 & -0.01 & -0.04 & 0.05 & -0.04 & -0.04 & 0.08 & 0.03 & -0.02 & 0.04 & 0.04 & 0.02 & 0.01 & -0.03 & -0.05 & -0.02 & 0.02 & 0.00 & 0.00 & 0.00 & -0.03 & 0.03 & -0.02 \\
\hline U22 & -0.08 & -0.04 & -0.05 & -0.07 & -0.03 & -0.05 & -0.04 & -0.07 & -0.01 & 0.02 & -0.03 & -0.05 & 0.01 & 0.02 & -0.10 & -0.07 & -0.03 & 0.08 & -0.08 & 0.00 & -0.07 & -0.06 & -0.02 & -0.01 \\
\hline U23 & -0.06 & -0.04 & 0.00 & -0.06 & -0.04 & 0.00 & -0.01 & 0.02 & 0.04 & 0.01 & -0.02 & -0.01 & 0.01 & 0.00 & -0.08 & -0.06 & -0.07 & 0.04 & -0.11 & -0.06 & -0.03 & -0.05 & -0.03 & -0.05 \\
\hline U24 & 1.00 & -0.07 & 0.01 & 0.19 & -0.03 & -0.02 & 0.00 & 0.06 & 0.05 & 0.00 & -0.04 & 0.03 & 0.01 & -0.03 & -0.07 & -0.04 & -0.04 & -0.05 & -0.08 & -0.06 & -0.04 & -0.04 & -0.03 & 0.01 \\
\hline U25 & -0.07 & 1.00 & -0.01 & -0.04 & 0.00 & -0.05 & -0.03 & -0.01 & 0.04 & 0.05 & -0.04 & -0.02 & 0.05 & 0.00 & -0.07 & -0.07 & -0.04 & -0.06 & -0.02 & -0.01 & 0.00 & -0.02 & 0.01 & 0.11 \\
\hline U26 & 0.01 & -0.01 & 1.00 & -0.02 & -0.02 & 0.01 & -0.00 & 0.01 & 0.01 & -0.03 & 0.04 & 0.10 & 0.06 & 0.05 & 0.02 & 0.07 & 0.03 & 0.04 & -0.06 & 0.02 & -0.02 & -0.01 & -0.02 & -0.10 \\
\hline U27 & 0.19 & -0.04 & -0.02 & 1.00 & -0.03 & -0.07 & -0.00 & 0.07 & 0.09 & -0.02 & -0.08 & 0.14 & -0.01 & -0.04 & 0.10 & -0.04 & -0.04 & -0.01 & -0.11 & -0.08 & -0.12 & -0.07 & -0.03 & -0.04 \\
\hline U28 & -0.03 & 0.00 & -0.02 & -0.03 & 1.00 & 0.03 & 0.00 & -0.04 & -0.02 & 0.00 & 0.04 & 0.00 & -0.04 & 0.02 & 0.02 & 0.03 & 0.05 & -0.02 & 0.00 & 0.06 & -0.02 & 0.02 & 0.01 & 0.05 \\
\hline C1 & -0.02 & -0.05 & 0.01 & -0.07 & 0.03 & 1.00 & 0.44 & -0.17 & -0.52 & 0.04 & 0.38 & -0.03 & 0.06 & -0.02 & 0.05 & 0.05 & 0.06 & 0.02 & 0.10 & 0.01 & 0.08 & 0.04 & -0.01 & 0.00 \\
\hline C2 & 0.00 & -0.03 & -0.00 & -0.00 & 0.00 & 0.44 & 1.00 & -0.14 & -0.37 & 0.05 & 0.20 & 0.03 & 0.06 & -0.03 & 0.01 & 0.01 & 0.02 & 0.06 & 0.06 & 0.00 & 0.06 & 0.07 & 0.00 & 0.00 \\
\hline C3 & 0.06 & -0.01 & 0.01 & 0.07 & -0.04 & -0.17 & -0.14 & 1.00 & 0.22 & -0.24 & 0.12 & 0.11 & -0.05 & 0.12 & 0.02 & -0.01 & -0.04 & 0.04 & -0.12 & -0.02 & -0.04 & -0.17 & -0.02 & -0.16 \\
\hline C4 & 0.05 & 0.04 & 0.01 & 0.09 & -0.02 & -0.52 & -0.37 & 0.22 & 1.00 & -0.13 & -0.27 & 0.08 & -0.09 & -0.03 & -0.02 & -0.04 & -0.09 & -0.04 & -0.12 & -0.07 & -0.11 & -0.05 & -0.01 & 0.01 \\
\hline C5 & 0.00 & 0.05 & -0.03 & -0.02 & 0.00 & 0.04 & 0.05 & -0.24 & -0.13 & 1.00 & -0.09 & -0.01 & 0.11 & -0.04 & -0.06 & -0.01 & -0.02 & 0.01 & -0.02 & -0.01 & -0.06 & 0.02 & 0.02 & 0.00 \\
\hline C6 & -0.04 & -0.04 & 0.04 & -0.08 & 0.04 & 0.38 & 0.20 & 0.12 & -0.27 & -0.09 & 1.00 & -0.01 & 0.08 & 0.08 & -0.03 & 0.04 & 0.04 & 0.06 & 0.05 & 0.02 & 0.17 & 0.01 & 0.00 & -0.08 \\
\hline C7 & 0.03 & -0.02 & 0.10 & 0.14 & 0.00 & -0.03 & 0.03 & 0.11 & 0.08 & -0.01 & -0.01 & 1.00 & 0.13 & 0.04 & 0.15 & 0.05 & 0.04 & 0.52 & -0.22 & -0.04 & -0.07 & 0.00 & -0.04 & -0.39 \\
\hline C8 & 0.01 & 0.05 & 0.06 & -0.01 & -0.04 & 0.06 & 0.06 & -0.05 & -0.09 & 0.11 & 0.08 & 0.13 & 1.00 & -0.02 & 0.02 & 0.00 & 0.00 & 0.06 & -0.02 & 0.01 & 0.02 & 0.01 & 0.01 & -0.10 \\
\hline P1 & -0.03 & 0.00 & 0.05 & -0.04 & 0.02 & -0.02 & -0.03 & 0.12 & -0.03 & -0.04 & 0.08 & 0.04 & -0.02 & 1.00 & 0.00 & 0.05 & 0.07 & 0.05 & -0.02 & 0.05 & 0.08 & -0.04 & -0.05 & -0.13 \\
\hline P2 & -0.07 & -0.07 & 0.02 & 0.10 & 0.02 & 0.05 & 0.01 & 0.02 & -0.02 & -0.06 & -0.03 & 0.15 & 0.02 & 0.00 & 1.00 & -0.06 & 0.02 & 0.06 & -0.02 & -0.02 & -0.05 & -0.03 & -0.02 & -0.14 \\
\hline P3 & -0.04 & -0.07 & 0.07 & -0.04 & 0.03 & 0.05 & 0.01 & -0.01 & -0.04 & -0.01 & 0.04 & 0.05 & 0.00 & 0.05 & -0.06 & 1.00 & 0.06 & -0.03 & 0.11 & 0.05 & 0.06 & 0.07 & 0.01 & -0.06 \\
\hline P4 & -0.04 & -0.04 & 0.03 & -0.04 & 0.05 & 0.06 & 0.02 & -0.04 & -0.09 & -0.02 & 0.04 & 0.04 & 0.0 & 0.07 & 0.02 & 0.06 & 1.00 & -0.00 & 0.02 & 0.08 & 0.04 & 0.01 & 0.04 & -0.02 \\
\hline P5 & -0.05 & -0.06 & 0.04 & -0.01 & -0.02 & 0.02 & 0.06 & 0.04 & -0.04 & 0.01 & 0.0 & 0.5 & 0.0 & 0.05 & 0.06 & -0.03 & -0.00 & 1.00 & -0.22 & -0.06 & 0.02 & 0.00 & -0.02 & -0.41 \\
\hline P6 & -0.08 & -0.02 & -0.06 & -0.11 & 0.00 & 0.10 & 0.06 & -0.12 & -0.12 & -0.02 & 0.05 & -0.22 & -0.02 & -0.02 & -0.02 & 0.11 & 0.02 & -0.22 & 1.00 & 0.20 & 0.17 & 0.34 & 0.13 & 0.33 \\
\hline P7 & -0.06 & -0.01 & 0.02 & -0.08 & 0.0 & 0.01 & 0.00 & -0.02 & -0.07 & -0.01 & 0.0 & -0.04 & 0.01 & 0.05 & -0.02 & 0.05 & 0.08 & -0.06 & 0.20 & 1.00 & 0.02 & 0.14 & 0.12 & 0.17 \\
\hline P8 & -0.04 & 0.00 & -0.02 & -0.12 & -0.02 & 0.08 & 0.06 & -0.04 & -0.11 & -0.06 & 0.17 & -0.07 & 0.02 & 0.08 & -0.05 & 0.06 & 0.04 & 0.02 & 0.17 & 0.02 & 1.00 & 0.17 & 0.04 & 0.02 \\
\hline P9 & -0.04 & -0.02 & -0.01 & -0.07 & 0.02 & 0.04 & 0.07 & -0.17 & -0.05 & 0.02 & 0.0 & 0.00 & 0.01 & -0.04 & -0.03 & 0.07 & 0.01 & 0.00 & 0.34 & 0.14 & 0.17 & 1.00 & 0.18 & 0.21 \\
\hline P10 & -0.03 & 0.01 & -0.02 & -0.03 & 0.01 & -0.01 & 0.00 & -0.02 & -0.01 & 0.02 & 0.00 & -0.04 & 0.01 & -0.05 & -0.02 & 0.01 & 0.04 & -0.02 & 0.13 & 0.12 & 0.04 & 0.18 & 1.00 & 0.13 \\
\hline P11 & 0.01 & 0.11 & -0.10 & -0.04 & 0.05 & 0.00 & 0.00 & -0.16 & 0.01 & 0.00 & -0.08 & -0.39 & -0.10 & -0.13 & -0.14 & -0.06 & -0.02 & -0.41 & 0.33 & 0.17 & 0.02 & 0.21 & 0.13 & 1.00 \\
\hline
\end{tabular}

Emboldened correlations are significant at $\mathrm{p}<0.05$ (two-sided tests). 


\section{Publications in the Report Series Research ${ }^{*}$ in Management}

\section{ERIM Research Program: "Marketing"}

\section{6}

The Effect of Feedback and Learning on DSS Evaluations

Ujwal Kayande, Arnaud de Bruyn, Gary Lilien, Arvind Rangaswamy and Gerrit Van Bruggen

ERS-2006-001-MKT

http://hdl.handle.net/1765/7302

Interaction Between Shelf Layout and Marketing Effectiveness and Its Impact On Optimizing Shelf Arrangements Erjen van Nierop, Dennis Fok and Philip Hans Franses

ERS-2006-013-MKT

http://hdl.handle.net/1765/7632

Institutional Forecasting: The Performance of Thin Virtual Stock Markets

Gerrit H. Van Bruggen, Martin Spann, Gary L. Lilien and Bernd Skiera

ERS-2006-028-MKT

http://hdl.handle.net/1765/7840

Irritation Due to Direct Mailings from Charities

Merel van Diepen, Bas Donkers and Philip Hans Franses

ERS-2006-029-MKT

http://hdl.handle.net/1765/7832

When Should Nintendo Launch its Wii? Insights From a Bivariate Successive Generation Model Philip Hans Franses and Carlos Hernández-Mireles

ERS-2006-032-MKT

http://hdl.handle.net/1765/7867

How Feedback Can Improve Managerial Evaluations of Model-based Marketing Decision Support Systems Ujwal Kayande, Arnaud de Bruyn, Gary Lilien, Arvind Rangaswamy and Gerrit van Bruggen

ERS-2006-039-MKT

http://hdl.handle.net/1765/7893

Moving in Social Circles - Social Circle Membership and Performance Implications

Willem Verbeke and Stefan Wuyts

ERS-2006-041-MKT

$\underline{\text { http://hdl.handle.net/1765/7899 }}$

Polysemy in Advertising

Stefano Puntoni, Jonathan E. Schroeder and Mark Ritson

ERS-2006-043-MKT

http://hdl.handle.net/1765/7898

Categorization by Groups

Rebecca W. Hamilton, Stefano Puntoni and Nader T. Tavassoli

ERS-2006-044-MKT

http://hdl.handle.net/1765/7900

Time-Series Models in Marketing

Marnik G. Dekimpe, Philip Hans Franses, Dominique M. Hansses and Prasad A. Naik

ERS-2006-049-MKT

$\underline{\text { http://hdl.handle.net/1765/7984 }}$

Dynamic and Competitive Effects of Direct Mailings

Merel van Diepen, Bas Donkers and Philip Hans Franses

ERS-2006-050-MKT

http://hdl.handle.net/1765/7948 
Multidimensional Scaling with Regional Restrictions for Facet Theory: An Application to Levi's Political Protest Data Patrick J.F. Groenen and Ivo A. van der Lans

ERS-2006-057-MKT

http://hdl.handle.net/1765/8045

The Quest for Citations: Drivers of Article Impact

Stefan Stremersch, Isabel Verniers and Peter C. Verhoef

ERS-2006-061-MKT

* A complete overview of the ERIM Report Series Research in Management: https://ep.eur.nl/handle/1765/1

ERIM Research Programs:

LIS Business Processes, Logistics and Information Systems

ORG Organizing for Performance

MKT Marketing

F\&A Finance and Accounting

STR Strategy and Entrepreneurship 